Undergraduates' Perceptions towards Psychology as a Science:

Differentiating explicit responses from implicit associations

by

Demi Plagianakos

A thesis submitted to the Faculty of Graduate and Postdoctoral Affairs in partial fulfillment of the requirements for the degree of

Master of Arts

in

Psychology

Carleton University

Ottawa, Ontario

(C) 2018

Demi Plagianakos 


\begin{abstract}
Research has primarily adopted explicit measures to examine students' view about the scientific status of psychology (Friedrich, 1996). Such measures have been found to be influenced by social desirability characteristics, however (Bartels et al., 2009). Moreover, explicit measures that are more direct by nature tend to yield less favorable and less scientific attitudes towards psychology compared to less direct ones (Hartwig \& Delin, 2003; Osborn et al., 2003; Provost et al., 2011; Webb, 1988). In this experiment, a go/no-go LDT was administered to both introduction to psychology students and upper year psychology majors to explore participants' scientific attitudes towards psychology at an implicit level (Perea, Rosa, \& Gomez, 2002). Using this procedure, psychology's implicit associations with "science", methodological terminology, as well as scientific and psychological attributes were assessed. The data showed that implicit "science-psychology" associations increase with greater exposure to the psychological curriculum. Furthermore, implicit associations between "psychology" and methodological terminology similarly strengthened over time. These results suggest that students' propensity associate psychology with science after obtaining greater psychology-specific education can be observed at a more basic level of processing.
\end{abstract}

Keywords: psychology, implicit attitudes, go/no-go lexical decision task 


\section{List of Content}

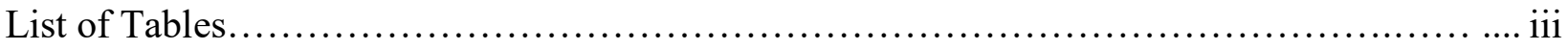

List of

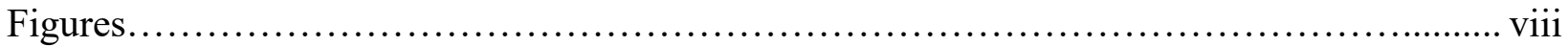

List of Appendices................................................................ vii

Undergraduates' Perceptions towards Psychology as a Science: Differentiating explicit responses

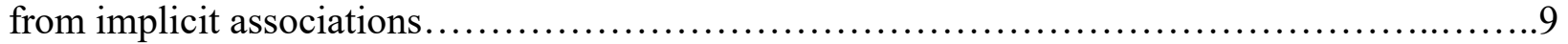

Scientific Topics........................................................ 12

Semantic network of science............................................ 13

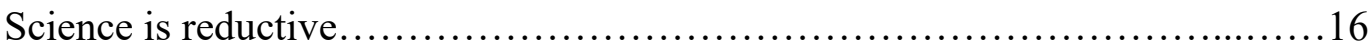

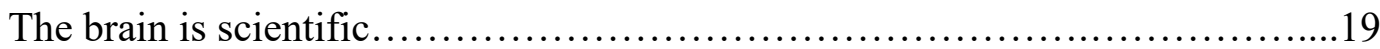

Scientific Attributes ..............................................................

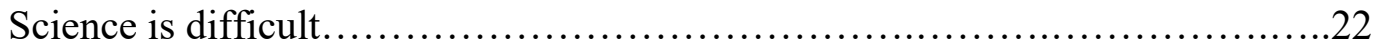

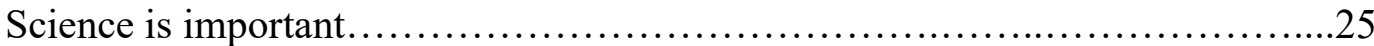

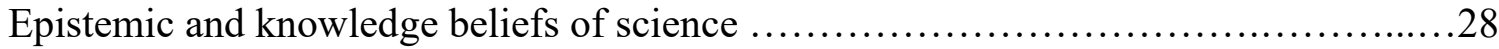

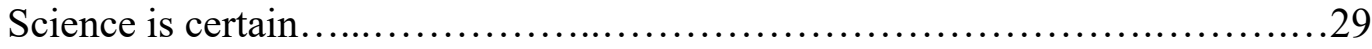

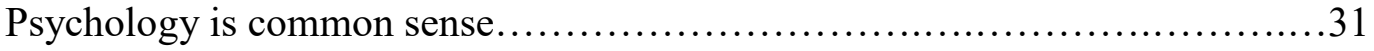

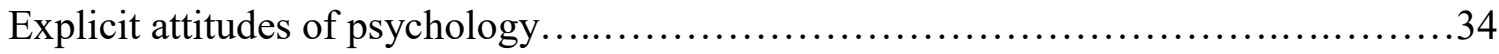

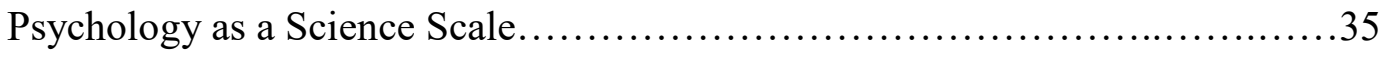

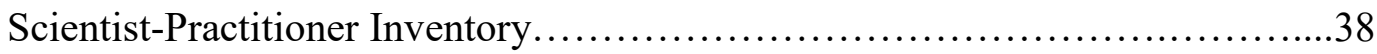

Implicit attitudes of science..............................................40

Lexical Decision Task. ..................................................44

Need for an implicit measure ................................................. 45

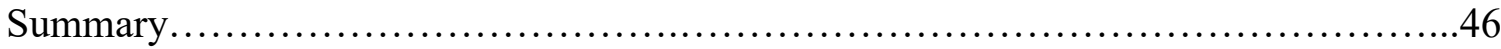




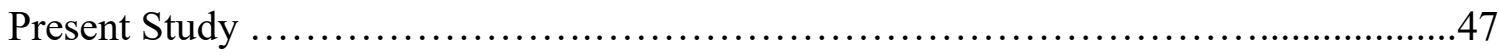

Hypotheses..............................................................48

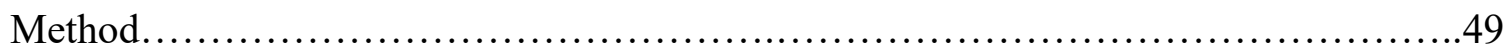

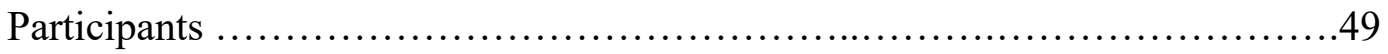

Measures..........................................................50

Go/no-Go Lexical Decision task...............................50

Psychology as Science Questionnaire...............................54

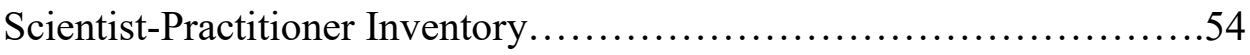

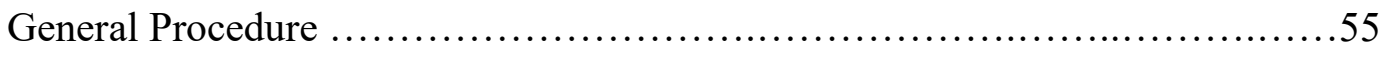

Results.................................................................. 55

Go/no-go LDT Response time analyses..............................55

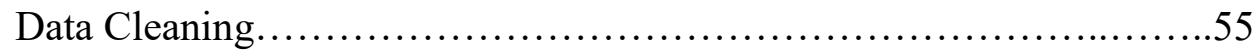

Correcting Reaction times to account for lexical processing effects......56

"Science" with disciplines.......................................57

Methodological Terminology.....................................59

Conceptions of Science.......................................61

Conceptions of Psychology....................................62

Science and subject matter................................... 64

Psychology with its topics of investigation........................66

Explicit Responses..................................................66

Psychology as a science scale...................................66

Scientist-practitioner Inventory...............................6 68

The correlations among the implicit and explicit measures...................68

Correspondence between PAS and SPI.............................69 
The correlations among implicit and explicit measures................70

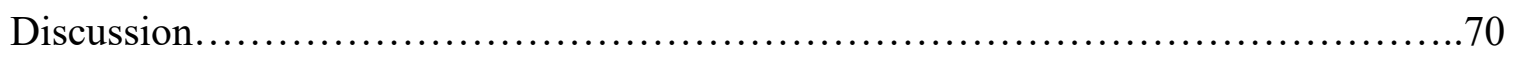

Psychology and science....................................... 71

Psychology and the scientific method............................ 72

Science and its topics of study................................. 73

The concept of science versus the concept of psychology .............74

Limitations and Future Directions................................. 76

Conclusion.................................................. 77

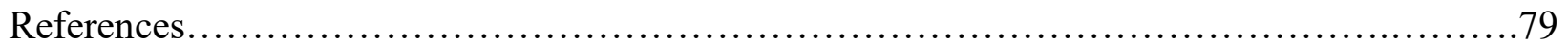




\section{List of Tables}

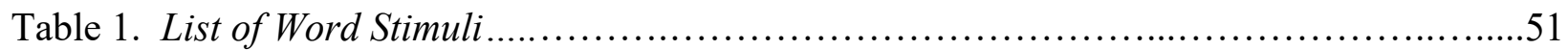

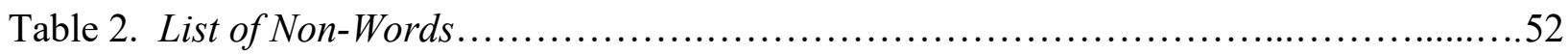

Table 3. PAS and SPI Scores for first and upper year students..............................67

Table 4. Correlations amongst measures for first year students ...........................69

Table 5. Correlations amongst measures for upper year students..........................69 


\section{List of Figures}

Figure 1. The procedure for the go/no-go lexical decision task.............................53

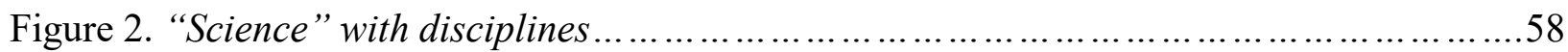

Figure 3. Methodological Terminology..............................................60

Figure 4. Scientific Terminology ..................................................62

Figure 5. Psychological Terminology.............................................63

Figure 6. Science with Topics of Investigation........................................64

Figure 7. Psychology with its Topics of Investigation...................................65 


\section{List of Appendices}

Appendix A. FSG between Scientific Disciplines and Subject Matter........................101

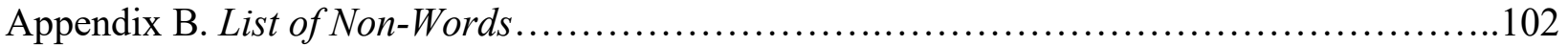

Appendix C. Word and Non-Words for Practice Trials................................. 103

Appendix D. Psychology as a Science Scale................................................104

Appendix E. Scientist - Practitioner Inventory ..................................... 105

Appendix F. Lexical Characteristics for Word Stimuli....................................106 
Undergraduates' Perceptions towards Psychology as a Science:

Differentiating explicit responses from implicit associations

Psychology has faced considerable controversy with regards to its scientific status (Benjamin et al., 1986; Lilienfeld, 2010; Ferguson, 2015). Many perceive it to be scientifically inferior to the hard sciences (See Fernandez-Duque et al., 2015; Keil, Lockhart, \& Schlegel, 2010; Krull \& Silvera, 2013; Weisberg et al., 2008, 2015), while others do not consider it to be a science at all (Berezow, 2012; Caswell, 2014; Lutus, 2013; Lutus, 2015). In attempts to understand psychology's image, researchers have assessed its semantic and associative relationship with other sciences. In a conceptual space comprised of academic disciplines, psychology students, faculty members, and the general public alike have displayed an inclination to conceptualize psychology as being more semantically similar to the humanities than to the sciences (Biglan, 1984; Plagianakos, 2015; Ryan, 2015; Webb \& Speer, 1986). Furthermore, given the limited extent that psychology and science elicit each other during free association (Morgan, 2015, 2017), they do not appear to be associatively related. Some research suggests that efforts to communicate psychology's employment of a scientific process to students may not be as effective in shaping their attitudes as one might believe (Sizemore \& Lewandowski, 2009). Although more advanced psychology students display an increase in scientific literacy, their propensity to consider psychology as a science does not similarly improve (Holmes \& Beins, 2009).

One must hold an accurate understanding of science to accurately represent psychology as a science (Stanovich, 2009). For that reason, an effective approach towards understanding psychology's unscientific image may be achieved by exploring people's general conceptualization of science. It is unlikely, however, that people evaluate science based on its defining criteria considering the complexity of this topic (e.g., See Chalmers, 2013). It is more 
probable that a variety of extraneous factors influence people's conceptualization of science. For instance, researchers have postulated that people may consider superficial details in evaluating the scientific credibility of academic disciplines (Fernandez-Duque et al., 2015; Krull \& Silvera, 2013). People fail to deliberately reflect on whether a discipline employs a scientific process and are more inclined to deliberate on whether a discipline fits their concept of science instead. Unfortunately, the literature clearly suggests that people's image of psychology shares little in common with people's conceptions of science. Three lines of research support this claim.

First, some research suggests that people evaluate the scientific status of a discipline by considering the topics that it investigates (Morgan, 2015). Specifically, people judge the subject matter that the hard sciences study to be more scientific than psychological phenomena (Krull \& Silvera, 2013). Second, research has identified particular characteristics that people ascribe to science but not psychology. Science is characterized as being the most difficult (Hernandez, 2015; Kessel, Rau, \& Hannover, 2006) and important academic domain (Janda et al., 1998). Psychology, however, is judged to be significantly easier than the hard sciences (Keil, Lockhart, \& Schlegel, 2010; Plagianakos, 2015) and one of the least important sciences (Janda et al., 1998). Finally, research has found that people's epistemic beliefs for science differ from those for psychology. Epistemic beliefs reflect people's views on the nature of knowledge (Hofer, 2000). The knowledge derived from scientific research is commonly regarded as being factually true while knowledge in psychology is seen as intuitive and derived from common sense (Estes et al., 2003; Lilienfeld, 2011; Hofer, 2000; Stanovich, 2009). Collectively, these elements contribute towards people's overall concept of science. What is concerning, however, is that these elements appear to be more denotive of science than the scientific method. Ultimately, this may interfere with people's ability to classify psychology as a science (Morgan, 2015, 2017). 
The extant literature is informative in highlighting the distinction between people's overall concept of science and psychology. This research, however, has been limited with respect to the measures that have been employed. Specifically, the research that has explored people's perceptions of psychology has more narrowly adopted explicit measures (Friedrich, 1996; Hartwig \& Delin, 2003; Wood, Jones, \& Benjamin, 1986). This has been proven problematic for several reasons. For instance, researchers have found that explicit measures, which are more direct by nature, yield less favorable and less scientific attitudes towards psychology compared to less direct ones (Hartwig \& Delin, 2003; Osborn et al., 2003; Provost et al., 2011; Webb, 1988). Moreover, one of the most widely implemented scales to measure students' belief that psychology is a science, Friedrich's (1996) Psychology as a Science Scale (PAS), appears to be influenced by social desirability characteristics (Bartels, Hinds, Glass, \& Ryan, 2009). Finally, although many have found evidence to suggest that psychology majors increasingly become aware that psychology is a science as they progress throughout the psychology curriculum (Amsel et al., 2011; Pettijohn et al., 2015), it has yet to be determined whether this change can similarly be observed at an implicit level.

The goal of this thesis is to explore students' implicit attitudes of psychology. This will be achieved by employing a lexical decision task (Meyer \& Schvaneveldt, 1971). The LDT measures the degree to which concepts are implicitly associated while not directly requiring participants to provide a deliberate response (Fazio \& Olson, 2003; Lane, Goh, \& Driver-Linn, 2012), effectively minimizing response biases and reducing social desirability effects (Cvenek, 2011; Fazio \& Olson, 2003; Nosek et al., 2002). Using this procedure, the extent to which psychology is associated with other sciences and people's concept of science can be assessed. This will enable a determination as to whether psychology's unscientific image can be explained 
by implicit processes. Moreover, it may determine which particular elements lead to a disassociation between psychology and the sciences. Finally, by implementing a LDT, the role of implicit attitudes on explicit responses regarding psychology's status as a science can be explored.

To accomplish these goals, I will first present research that has documented people's concept of science. Next, I will present the most commonly used explicit measures to assess psychology's image. Then, I will introduce implicit measures, their advantages over explicit measures, and present some of the research findings that have emerged by employing both methods. Subsequently, I will argue that an implicit measure will lead to a more comprehensive understanding of psychology's current public image. Finally, a go/no-go lexical decision task will be presented as a suitable method to explore the implicit attitudes of psychology as a science.

\section{Scientific Topics}

Research has provided evidence to suggest that some disciplines may be regarded as particularly scientific because of the topics that they investigate (Hopkins, Weisberg, \& Taylor, 2016). Specifically, the subject matter studied in the hard sciences is commonly considered more scientific than those investigated in the social sciences. This was demonstrated in Krull and Silvera's (2013) study where participants were presented with a variety of natural science topics (e.g., brain, solar flares) and behavioural science topics (e.g., attitudes, social interactions). Participants judged natural science topics to be significantly more scientific than behavioural ones. Thus, even without any indication as to whether these topics were investigated by means of an empirical process, people perceived certain subject matter to be more scientific than others. 
Moreover, natural science equipment (e.g., microscope, magnetic resonance imaging) was also judged to be more scientific than behavioural science equipment, like questionnaires.

Clearly, science is not defined by its subject matter or the tools it utilizes to investigate these subjects (Stanovich, 2013). Nonetheless, these stereotypes appear to be strong predictors of people's evaluations of science. In fact, they have presented themselves in people's schemas of scientists as well. For instance, Chamber's (1983) draw-a-scientist task has established that children as early as the kindergarten aged depicted scientists surrounded by stereotypical laboratory equipment (e.g., test tubes, microscopes, and telescopes) with captions that read that scientists were studying topics such as chemicals, germs, and diseases. Even undergraduate science majors depicted scientists in a similar fashion (Thomas, Henley, \& Snell, 2006).

Semantic network of science. Further research shows the significant influence that topics of study play in people's concept of science and it is exemplified more by research that has explored the semantic associates of science (Hernandez, 2015; Morgan, 2015, 2017). Arguably, this network should primarily consist of features that reflect the scientific method. If people more strongly associate science with the topics that it investigates, however, then it would suggest that their representation of science is inaccurate. Both free association and family resemblance studies have sought to compare the features associated with psychology and the hard sciences to understand their differences.

For instance, Morgan (2015) asked undergraduate students enrolled in an introductory psychology course to complete a discrete free association task. Participants were presented with scientific and non-scientific disciplines, and prompted to list the first word that came to mind. One might expect that this sample, derived from a course that instructs its students on psychology's employment of the scientific method, would be more inclined to generate scientific terminology. In fact, undergraduate students did produce a host of methodological terms. For 
instance, "hypothesis", "observation" "research", "study", and "experiment" were all present in the semantic network of science. And while it appears that undergraduates associated the sciences with an empirical approach, it should be noted that many of these associates were evoked for the cue "science" and not for scientific disciplines per se. In fact, only "experiment", "research", and "study" were ascribed to particular scientific disciplines (i.e., physics, chemistry, and psychology). "Study" was associated with other, non-scientific disciplines (e.g., history and theology). Thus, the only two methodological associates that were uniquely ascribed to scientific disciplines were "experiment" and "research". Encouragingly, psychology was assigned these features. Morgan's (2017) follow up study, which additionally sampled members of the general public, obtained similar results. Overall, these findings suggest that undergraduates acknowledge that science displays a specific methodological approach. Yet, they appear to be less able to recognize that scientific disciplines by extension engage in this process as well.

Although undergraduate students represented science with methodological terminology, they were much more likely to associate scientific disciplines with the topics that they investigate. For instance, Morgan (2015) found that the three strongest associates for psychology were "mind", "behaviour" and "brain". The same pattern of responses was found when examining the top associates for chemistry (e.g., chemical), neuroscience (e.g., brain), and biology (e.g., animals). One might expect the cue "science" to elicit a greater degree of methodological terminology compared to scientific subject matter. Yet, topics of investigation (e.g., evolution, molecule, and atom) were elicited to a greater extent. Similarly, Morgan's (2017) follow up study also found a tendency for people to conceptualize the sciences with the topics that they investigate. 
In a related study, Hernandez (2015) adopted a family resemblance approach to explore the semantic network of scientific disciplines exclusively. The first part of the study required participants to complete a free listing task, whereby they were asked to list as many scientific disciplines as they could. Using the top thirteen scientific disciplines generated from this study, a second group of participants completed a feature listing task. Participants were presented with these sciences and asked to list their properties, attributes, and characteristics. In contrast to the discrete free association task, participants were able to list all the features that came to mind, encouraged to list features other than topics, and under less time constraints. Accordingly, one might have expected this paradigm to elicit more methodological terminology than the free association studies. This was not found to be the case, however. Specifically, of the eight main features determined to be representative of the category "science", half of them reflected subject matter (i.e., humans, chemicals, development, and behaviour).

Collectively, both Morgan's $(2015,2017)$ and Hernandez's (2015) studies have established the most salient features of science. Given that scientific disciplines including psychology were associatively related to methodological terminology, it is unlikely that psychology's unscientific image can be explained by the belief that it does not use the scientific method. Rather, the overrepresentation of subject matter in the semantic network may suggest that people's concept of science dominated by extraneous factors irrelevant to an empirical process.

If this is true, then it is necessary to understand how psychology's subject matter differs from that of the other sciences. In making this comparison, one might be surprised to learn that psychology and neuroscience were found to study a similar subject matter. For instance, "brain" and "mind" were amongst the top three associates for both psychology and neuroscience (Morgan, 2017). Similarly, neurology and psychology shared a high family resemblance with 
one another, given that they were both attributed to studying "humans" and "behaviour" (Hernandez, 2015). Despite their similarities in subject matter, neuroscience is judged to be scientifically superior to psychology (Fernandez-Duque et al., 2015; Hopkins, Weisberg, \& Taylor, 2016). People possibly grant neuroscience with greater scientific credibility because of the reductionist approach that it takes in explaining psychological phenomena. If this is the case, at least some characteristics of a discipline's subject matter may influence judgements of scientific quality.

Science is reductive. Reductionist theories draw upon the Comte's (1853) hierarchy of sciences. Comte believed that the sciences could be organized as a function of the generality and complexity of the phenomena they seek to investigate. Psychology and neuroscience were not established disciplines at the time. Researchers that have included these disciplines, however, typically order the hierarchy with sociology at the top, followed by psychology, neuroscience, biology, chemistry, and physics (Hopkins, Weisberg, \& Taylor, 2016). Disciplines higher up on the hierarchy are considered to study phenomena at a broader or more macroscopic level, while those at the bottom of the hierarchy are considered to study phenomena at a microscopic level (Cacioppo \& Berntson, 1992). Reductionist theories posit that phenomena investigated by sciences at higher levels can be fully explained by referring to explanations that utilize phenomena at lower levels. Each science is dedicated to studying constructs that inherently differ in their complexity and generality. The belief that psychological phenomena such as behaviours or emotions can be understood by a physical explanation omits the context in which behaviours and emotions are embedded. For that reason, some have argued that, too often, scientists wrongfully claim to understand how causation works, specifically between psychology and biology (Miller, 2010). Still, others believe that reductionist theories provide a multilevel 
and integrative approach to research, specifically for psychology whose theories may be consolidated by acknowledging the biological basis of mental and behavioural experiences (Cacioppo \& Berntson, 1992).

At the time the hierarchy was presented, Comte (1853) believed that sociology was the most encompassing discipline, thus, referred to it as the "queen of the sciences". Ironically, the status of the sciences has been completely reversed, with physics now being considered the most scientifically credible. In fact, some have claimed that psychologists suffer from "physics envy" (Howell, Collisson, \& King, 2014). Thus, superficially, it seems as though the hierarchy has been used to determine the scientific status of disciplines. Researchers have long been interested in determining whether the sciences do in fact differ in their degree of empiricism (Conant, 1950) and their employment of a specific paradigm (Storer, 1967). In large, there does not appear to be any evidence to suggest that the sciences along the hierarchy differ in the degree to which their paradigms are systematically developed (Cole, 1983). The sciences have been found to differ in their theory-to-law ratios, peer evaluation consensus, and consultation rate, however (Simonton, 2004). Yet, based on these factors, psychology has been found to behave more like a "hard" science (e.g., biology) than a "soft" science (e.g., sociology). Moreover, with respect to terminological sharing, or the extent that the sciences uniquely develop their own independent laws and concepts, psychology similarly has been proven to perform comparably to the hard sciences (Roeckelein, 1997). Thus, any beliefs that psychology is scientifically inferior to the hard sciences based on objective factors of scientific quality appear to be unwarranted.

Nonetheless, people intuitively display a preference towards reductionism. Research has suggested that judgements of both disciplinary importance (Janda et al., 1998) and academic difficulty conform to the hierarchy of science, even at a young age (Keil et al., 2010). People's attraction to reductionism may best be exemplified by considering research on the "seductive 
allure" of neuroscience. This effect emerges when people are provided with research articles that describe psychological phenomena. When they contain neuroscientific information, they are judged to be more credible, compelling, satisfying, and scientific (Fernandez-Duque et al., 2015; Rhodes et al., 2014; Weisberg et al., 2008; Weisberg et al., 2015). Moreover, neuroscientific information appears to impair people's ability to evaluate theories about psychology. For instance, participants are less able to distinguish good explanations from bad ones (i.e., circular statements) when they contain neuroscience (Fernandez-Duque et al., 2015; Weisberg et al., 2008; Weisberg et al., 2015). While neuroscience experts do not fall prey to the allure, neuroscience students and novices display this effect (Weisberg et al., 2008). Furthermore, those with superior reasoning skills, thinking dispositions, and analytic skills are not immune to the allure, although the effects are more pronounced for those with beliefs congruent with the research articles claims (Fernandez-Duque et al., 2015; Rhodes et al., 2014).

Two leading theories have been brought forth to explain the allure. One theory speculates that the allure arises because people prefer a physical explanation of abstract phenomena (Keil, 2006; McCabe \& Castel, 2008). Specifically, when people are provided with a physical explanation that they can readily visualize, they may be more inclined to believe that this explanation is more scientifically credible than one that is theoretically oriented. By this account, the allure is specific to the pairing of psychology and neuroscience (Fernandez-Duque et al., 2015). A second theory contends that the allure is the result of any scientific structure that adopts a lower level explanation of higher-level phenomena. Therefore, this theory speculates that the allure can more generally be extended to all sciences.

Hopkins, Weisberg, and Taylor (2016) sought out to determine whether a reductionist explanation could account for the seductive allure of neuroscience. Thus, their study assessed whether it was specific to the neuroscience and psychology pairing (e.g., a preference for 
explanations of psychological phenomena that includes neuroscience information) or whether it extended to other scientific disciplines as well (e.g., a preference for explanations of biological phenomena that includes information about chemistry). The participants read explanations that were derived from a variety of sciences at different levels of the hierarchy (organized with social science at the top followed by psychology, neuroscience, biology, chemistry, and physics). The explanations were either good or bad, and were either horizontal or reductive by nature. Horizontal explanations were those that relied exclusively on the science's own subject matter. In contrast, reductive explanations referenced information drawn from the science directly below in the hierarchy.

The participants judged reductive explanations to be significantly better than horizontal ones. The magnitude of this effect was the largest for the psychology and neuroscience pairing. Thus, the combination of a reductionist explanation that additionally provided a physical basis for abstract phenomena appeared to be particularly persuasive. Still, there were marginally significant effects between the hard sciences as well (i.e., physics, chemistry, and biology). Interestingly, participants explicitly referenced the reductive structure of the explanations when justifying their ratings, with undergraduates doing so to a significantly greater extent. These findings demonstrate that at least some property of subject matter, in this case, the level of analysis researchers employ, has an effect on people's evaluations of science. Furthermore, this research suggests that more tangible subject matter, rather than abstract, may be stereotyped as more scientific. Thus, it is possible that neuroscience's greater use of explanations that reference the brain may lead to the allure.

The brain is scientific. The U.S. Congress declared that the 1990's was to be the "Decade of the Brain". This announcement was likely sparked by the rapid development of technological advancements that made it possible to map out neural structures (Cacioppo \& 
Berntson, 1992). Some have characterized brain images as the "archetype of the prototypical scientific image" (Baker et al., 2015, p. 253; Feigenson, 2006). This may explain why neuroscience, the discipline most strongly associated with the brain (Morgan, 2017), is correspondingly judged to be the most prestigious science (Fernandez-Duque et al., 2015; Hopkins, Weisberg, \& Taylor, 2016). Furthermore, research has suggested that the allure of neuroscience stems from people's appeal to explanations of the mind that reference the brain (Fernandez-Duque et al., 2015). For instance, when participants were asked to explain why they judged neuroscience explanations to be superior, many alluded to the "brain" and particular "lobes", with a greater tendency for undergraduate students to do so. Weisberg et al. (2015) concluded that "any reference to the brain was sufficient to make an explanation seem more satisfying than a logically parallel explanation without such reference" (p. 439).

Although it is controversial, some research suggests that the inclusion of brain images in research articles enhances judgements about the quality of their scientific reasoning. For instance, undergraduate students were shown mock scientific articles that were accompanied by brain images, a bar graph, or no visual display. The participants thought that the articles with the brain images displayed the best scientific reasoning (McCabe \& Castel, 2008) and produced the highest ratings of scientific credibility (Ikeda, Kitagami, Takahashi, Hattori, \& Ito, 2013). These results have been extended to the legal context given that participants that have taken part in mock jury trials were more likely to find a defendant not guilty by reason of insanity when neuroimages (that referenced the brain) were used to present their case (Gurley \& Marcus, 2008). Similar studies have found that participants expressed greater self-reported comprehension on articles that were accompanied by brain images despite no significant differences in actual text comprehension (Ikeda et al., 2013). It has been suggested that reference to the brain may allow 
people to visualize components of a system that in turn leads to a greater belief that they can understand this system (Keil, 2006).

Despite these few studies, which provided evidence to suggest that brain images are particularly persuasive, the findings have been heavily criticised given their failures to replicate (Farah \& Hook, 2013). For instance, a series of ten replications using the same material as McCabe and Castel (2008) with nearly 2000 participants found little effect of brain images (Michael et al., 2013). Others have also found no significant differences in scientific judgements for articles with or without fMRI images (Gruber \& Dickerson, 2012). Furthermore, no independent effect of neuroimages above and beyond those found for neuroscientific information have been clearly established (Fernandez-Duque et al., 2015; Greene \& Cahill, 2012; Hook \& Farah, 2013; Michael et al., 2013; Schweitzer et al., 2011; Schweitzer \& Saks, 2011). Although research has failed to replicate the brain's effect within the legal context, participants have claimed that neuroimages would be a useful part of evidence in criminal defenses (Greene \& Cahill, 2012). Collectively, this research suggests that brain images themselves may not lead to increased judgements of scientific credibility. Nonetheless, the brain appears to be strongly representative of people's conception of science.

\section{Scientific Attributes}

Researchers have shown that the characterization of science as difficult and important is paramount in the concept of science. Although researchers have found these evaluations to be particularly representative of science, psychology is not characterized in a similar fashion. In fact, psychology is judged to be one of the easiest and least important sciences (Janda et al., 1998; Plagianakos, 2015). It is possible that psychology's unscientific image can be explained by the fact that it is not ascribed these attributes. 
Science is Difficult. Research has shown that people judge psychology to be a significantly easier discipline than the hard sciences (Hernandez, 2015, Morgan, 2015, 2017, Plagianakos, 2015). Moreover, people tend to evaluate the gap in knowledge between an expert and a layperson to be rather modest within psychology compared to the hard sciences. These results have been found in the general public, faculty members (Janda et al., 1998; FernandezDuque et al., 2015), and even children (Keil et al., 2010). The bias to perceive psychology as easy is particularly strong for non-psychology majors and minors (Brinthaupt, Hurst, \& Johnson, 2016). In contrast, high school students typically regard the sciences and mathematics as being the most academically challenging subjects (Watson, Mcewen, \& Dawson, 2006). Furthermore, introduction to psychology students associated many scientific disciplines with "difficulty" (Morgan, 2015). They did not do so for psychology, however. In fact, many undergraduates associated psychology with the feature "easy" (Morgan, 2017).

Some have interpreted sciences' characterization as difficult as a reflection of the intelligence and skill people believe are required to master these domains (Kessel, Rau, \& Hannover, 2006; Osborne, Simons, \& Collins, 2000, 2003). What is problematic about this characterization, however, is that it may be a stronger representational feature of science than the scientific method (Hernandez, 2015; Morgan, 2015, 2017). For instance, "difficult" was found to be the most dominant characteristic feature of science (Hernandez, 2015) as well as one of its strongest associates (Morgan, 2015, 2017). Moreover, "intelligence" was also a characteristic feature of the category science (Hernandez, 2015) and its third strongest associate (Morgan, 2017).

Researchers have attempted to identify why so many people believe science is difficult. 
Some have suggested that this attitude is rooted in people's achievement in science subjects. Specifically, inferior performance in the sciences relative to other academic disciplines may result in the belief that it is difficult (Cheng, Payne, \& Witherspoon, 1995; Roberts, 2002). Yet, others have speculated that this belief is fostered by the technical language used to explain its subject matter (Johnstone, 1991) and the mathematical components incorporated in many science curricula (Mutch, 2010). These seem like plausible explanations considering that adolescents stated that the greatest difficulties they faced in science classrooms were the language barrier, the complexity of the concepts, and the perquisite for understanding mathematical concepts, particularly for physics and chemistry (Osborne \& Collins, 2000).

It is likely that a combination of these factors may contribute towards sciences' characterization as difficult for older pupils. Keil et al.'s (2010) research suggests, however, that the propensity to evaluate the sciences as "difficult" and psychology as "easy" emerges at a young age. This was demonstrated after presenting children ranging from kindergarten to eighth grade a variety of phenomena pertaining to physics, chemistry, biology, psychology, and economics. The children indicated how easy it was to understand each of the topics. There were no significant differences in difficulty judgements across the hard sciences at any of these ages. Beginning in the second grade, however, there appeared to be a bias for children to judge psychological phenomena to be significantly easier than hard science phenomena. A follow up experiment suggested that this bias may arise as the result of its topics being more close to immediate experience. It is possible that people can modify and accommodate their understanding of concepts that they already have acquired experiences for, but have greater difficulties doing so for topics that fall beyond the scope of their everyday lives (Johnstone, 1991). The results appeared to support this notion given that when children were presented with 
an array of phenomena drawn exclusively from psychology. Those that could be more closely experienced were judged to be easier to understand. Thus, for young children that have yet to be exposed to any social or contextual factors that may lead to their believing that science is difficult, intrinsically, there appeared to be a bias to judge science as more difficult than psychology.

Nonetheless, people's belief that psychology is an easy field of study has been described as merely an illusion (Rozenblitz \& Keil, 2002). For instance, junior high, high school, and college students tend to be overconfident in their comprehension of psychology texts (i.e., they believe that they understand these text more than they actually do), but under confident in their understanding of physics and chemistry texts (i.e., they believe they understand less than they actually do) (Zimmerman et al., 2007). These results suggest that people's conception of science, specifically that science is difficult, may impede an accurate evaluation of one's own comprehension. Moreover, this suggests that the perception that psychology is easy appears to be unwarranted. It is worth noting that undergraduate students that displayed greater naïve views of science were also more likely to view psychology as easy (Provost et al., 2011).

Finally, it should be noted that alternative explicit measures reached different conclusions with respect to psychology’s academic difficulty. For instance, Provost et al. (2011) asked undergraduate students to indicate whether they agreed or disagreed with the statement that "psychology is an easier subject to study than other science subjects". Participants scored near the midpoint indicating that they neither agreed nor disagreed with this statement. This variation in responses could be explained by the fact that this question described psychology as a science. Thus, participants might have been more likely to accurately conceptualize psychology as a science when providing their responses. In contrast, researchers that have utilized Likert scales 
and asked participants to judge a discipline's degree of difficulty when they are presented in isolation have found that the hard sciences are judged to be significantly more difficult than psychology (Plagianakos, 2015; Hernandez, 2015). These variations in explicit responses raise concerns as to whether researchers can accurately capture students' beliefs about psychology with the measures they employ.

Science is important. Science has undoubtedly made significant contributions to society. Thus, it is not surprising that people view science as important. Interestingly, parents' perceived value of science was found to predict the opinion of their children and also related to interests in science and scientific literacy (Acosta \& Hsu, 2014). Even adolescents believed that science offers the greatest social benefits to society (Watson, Mcewen, \& Dawson, 2006). For instance, nearly $90 \%$ of pupils aged 14 to 16 judged science to be either "important" or "very important" in everyday life (The Research Business, 1994). Notwithstanding this belief, however, additional research has shown that teenagers failed to acknowledge the value of learning science in school (Osborne \& Collins, 2000). For instance, many saw little importance in learning chemistry, in large part because they claimed that memorizing the periodic table was not of practical use. What is more, participants that acknowledged the importance of science were only able to provide limited examples of its contributions and seldom discussed the scientific process responsible for producing these important advancements. Thus, although importance is a stereotypical feature of science, people generally display a lack of ability in explicitly explaining why.

What is troubling about this belief is that psychology, as a science, is not similarly granted credit where it is due with regards to significance of its scientific accomplishments. This fact emerged from Janda et al.'s (1998) study that sought out to assess the degree that 
psychology is perceived to be important relative to other disciplines. Participants judged physics, chemistry, biology, medicine, economics, sociology, and psychology on their importance. Subsequently, participants were asked to name the most important contributions each discipline has made to society. Contrary to the task instructions, when naming psychology's contributions, some participants actually claimed that it was responsible for creating problems for society. Nonetheless, participants generally named psychological contributions with equal frequency (between $46-55 \%$ ) to that of the hard sciences. Upon examining the types of contributions people listed for psychology, it was evident that they did not reflect its scientific accomplishments. Rather, they reflected the role of psychology's practitioners, like treating mental illnesses. The confusion between the practitioner and scientific domains of psychology is barely a new issue (Dempsey, 2007; Hartwig, 2003; Murstein \& Fontain, 1993; Webb \& Speer, 1986). Participants unexpectedly, however, displayed a misunderstanding towards the roles of other scientists as well; for instance, believing that space travel was a contribution made by physicists. Despite having an inaccurate representation of what physicists or psychologists actually do, participants still judged physics as having made significantly more important contributions to society. In fact, sociology and psychology were judged to be the least important disciplines, while the hard sciences and medicine were judged to be the most important domains.

These findings may be taken as evidence that people do not necessarily deliberate on their judgements of science, but rather activate their concept of science to provide explicit responses. This seems especially likely considering research that asked participants to judge natural science scenarios on their importance (Krull \& Silvera, 2013). Participants rated scenarios that were completely devoid of a scientific outcome (e.g., Dr. Johnson studies hormones. To do this research, Dr. Johnson uses syringes) to be more important than comparable 
behavioural science research scenarios (e.g., Dr. Rogers studies social interactions. To do this research Dr. Rogers uses questionnaires). Thus, even without being provided with adequate information to evaluate the importance of these scenarios, participants were nonetheless willing to claim that research more rooted in the hard sciences was more important than research more typically investigated in psychology.

There are particular populations where one might expect greater judgements of psychology's importance. For instance, psychologists and psychology majors should be more readily aware of the contributions their area's research has made to society. Consequently, they ought to be more willing to consider the discipline to be an important one. Research has demonstrated, however, that this may not be the case. For instance, many faculty members that participated in Janda et al.'s (1998) study indicated having taken extensive coursework in psychology. Yet, they still displayed similar pattern of judgements to the general public. Similarly, psychology students judged psychology to be significantly less important than the hard sciences (Hernandez, 2015; Morgan, 2015, 2017; Plagianakos, 2015). Finally, perhaps the most disconcerting finding is that psychologists have been found to display difficulties naming important contributions made within their own field (Wade, 1982).

It should be noted, however, that people's judgements towards psychology's degree of importance depend on the type of measures researchers employ (Hartwig \& Delin, 2003; Webb, 1988). While direct measures have been described as inviting stereotypes, yielding less favorable attitudes towards the discipline, indirect measures have generally produced more favourable attitudes (Hartwig \& Delin, 2003; Webb, 1988). For instance, one study compared people's perceptions of psychologists relative to other professions (i.e., psychiatrists, teachers, lawyers, general practitioners, and nurses) and more directly asked them how important each profession was (i.e., "How much do you think we need the following professionals and the 
services they provide?"). Psychology was judged to be the least needed profession. A prototype approach was also implemented as an indirect measure. Thus, participants were provided with a list of positive adjectives (e.g., dedicated, committed, well trained, helpful, caring, curious, intelligent, knowledgeable, etc.) and asked to judge how typical each of these characteristics were of the professions. More favourable attitudes towards psychologists were found using this indirect approach. Given that researchers have differentially characterized the public's attitudes towards psychology based on the measures they employ supports the need for an implicit account of psychology's image. An implicit measure appears to be particularly suitable given that the public has demonstrated a lack of deliberate consideration when providing explicit responses surrounding psychology.

\section{Epistemic and knowledge beliefs of science}

The elements that embody people's concept of science presented thus far have been unrelated to the scientific method. What Gardner (1975) refers to as "scientific attitudes", however, do encompass more complex beliefs about the scientific process. These scientific attitudes involve people's need to question and understand, a consideration for empiricism, and a need for verification (Osborne, Simons, \& Collins, 2003). These types of attitudes have more commonly been investigated by examining people's epistemic beliefs; that is, their views on knowledge and their understanding of how knowledge is acquired (Hofer, 2000; Fulmer, 2014). Some common dimensions that have been used to assess epistemic beliefs include people's justifications of knowledge (King \& Kitchner, 1994), source of knowledge (Perry, 1970; Hofer, 2000), and beliefs on the simplicity and certainty of knowledge (Schommer, 1994). Along these dimensions, epistemic beliefs have been found to be domain dependent (Stodolsky et al., 1991). That is, the nature and the acquisition of knowledge in psychology and science are perceived to 
differ. Specifically, undergraduate students generally regard the knowledge derived from science as stemming from external authorities who are able to make knowledge claims with a greater degree of certainty (Hofer, 2000). People consider psychological phenomena to be more intuitive and subjective, however (Lilienfeld, 2012; Stanovich, 2009). As a result, people tend to believe that they, themselves, can be the arbiters of psychological knowledge and rely on both personal experiences and their own belief systems to make psychological claims (Estes et al., 2003).

Science is certain. When people attempt to assert their views as valid, it is common to encounter expressions such as "but science has shown that" or "it's a scientifically proven fact". These remarks give the impression that one can accept scientific claims without question. This may explain why "fact" has been found to be a strong associate of "science" (Morgan, 2017). To assess how such beliefs compare relative to psychology, Hofer (2000) administered two epistemic belief questionnaires to undergraduate psychology students. Participants completed one by reflecting on psychology and another while reflecting on the sciences more generally. Psychology students believed that truth was more attainable and knowledge was less changing in the sciences than in psychology. For instance, undergraduates were more likely to endorse statements such as "if you read something in a textbook for this subject you can be sure it's true" and "in this subject, most work has only one right answer" for the sciences than in psychology. It is possible that the association between science and mathematics is responsible for this discrepancy. For instance, similar research found that knowledge in mathematics was viewed as more fixed, certain, and unchanging than psychology (Schommer \& Walker, 1995). Provost et al. (2011) noted that knowledge refutability, or the ability to recognize that knowledge is subject to change, does increases as students advance from their first, second, to third year of their 
undergraduate education. They continued, however, to display a naïve understanding of science. Thus, there appears to be a discordance between knowledge and attitudes. Specifically, acquiring more sophisticated knowledge in science does not necessarily serve to change scientific attitudes.

It is possible that science is associated with a greater connotation of certainty as a result of the way that information is presented to students in an academic setting. To explore this possibility, Smyth (2001) and Collisson et al. (2015) examined differences in the way information is presented in psychology, biology, physiology, and mathematics textbooks. Smyth's study showed that psychology textbooks made significantly greater use of references and citations compared to the other sciences, even when presenting exactly the same information. Thus, psychology may present evidence where other sciences present facts. In doing so, Smyth argued that "psychology textbooks deny themselves the certainty of science" (p. 409). Collisson et al.'s study similarily found a greater amount of citations in psychology textbooks. Notably, undergraduate students perceived psychology as more scientifically credible when it contained a greater amount of citations. For biology, however, scientific credibility was not affected by its use of citations.

Not only textbooks, however, have been found to differentially present information. Within an academic setting as well, differences in teaching psychology and other sciences have been observed. For instance, some contend that faculty members who teach what has been characterized as the hard sciences are less likely to present information from a variety of perspectives compared to faculty members in the soft sciences, including psychology (Braxton \& Hargens, 1996). Some speculate those in the softer fields feel a greater need to display an openness to a variety of methodological approaches due to their lower consensus rates of knowledge compared to in the harder fields (Del Favero, 2006). Osborne and Collins' (2000) 
study demonstrated that elementary and high school students recognize that science is taught in an authoritative manner. This was demonstrated by conducting focus groups on pupils to assess their attitudes toward science education. A common complaint expressed by students was that teachers were apparently reluctant to satisfy students' request for additional explanations. For instance, some students claimed that their teachers asked them to simply accept the information that they were being taught. This pedagogical approach may foster the notion that science is derived from the teachers' authority. This may also explain why many students claimed that in science "you've just got to accept the facts" (p. 25) and that "there's one answer and you've got to learn it" (p. 25). Others have similarly argued that science education often consists of a collation of facts that are presented in a manner that makes them appear fixed and unchanging (Driver, Newton, \& Osborne, 2000). Students, however, expressed a desire to go beyond the memorization of facts. For instance, students wanted to discuss scientific questions, but were unable due to a lack of opportunity in the classroom. Although science is built on skepticism, open dialogue, and argumentation, many have argued that these elements are lacking in science education (Driver, Newton, \& Osborne, 2000; Khun, 1993).

Psychology is common sense. In contrast to the epistemic beliefs that scientific knowledge is certain and derived from authority, the nature of knowledge in psychology is largely viewed as intuitive. For instance, Lilienfeld (2012) presented six of the most common criticisms towards psychology, where he stated that one reason the discipline is not considered a science is because its findings are perceived as "merely common sense". Others have similarly observed that this belief may constitute psychology's largest barrier towards obtaining a scientific status (Stanovich, 2009). Moreover, "intuitive" has been found to be associatively related to psychology (Morgan, 2017). Given people's acceptance of many psychological myths, 
however, it seems unlikely that phenomena in psychology are merely common sense (Gardner \& Brown, 2013; Lilienfeld, 2010). Nonetheless, nearly $85 \%$ of the general population believed that "daily life experiences afforded them adequate training in psychology" (Wood, Jones, \& Benjamin, 1986). Some even claimed that "what psychologists have to say cannot be believed and that people should rely instead on their common sense" (Janda et al., 1998, p.

141). Others have pointed out that people similarly hold misconceptions about the properties of physics, but yet are more likely to acknowledge that their intuitions have mislead them in that domain compared to in psychology (Stanovich, 2009). Psychologists are not immune to these beliefs, given that some actually suggest that common sense may be taken as a valid source of empirical data (Kluger \& Tikochinsky, 2001; Redding, 1998).

These beliefs undermine psychologists' efforts to scientifically investigate their subject matter. Additionally, people will also see little value in employing the scientific method towards understanding psychological phenomena. For instance, a reliance on personal experiences and testimonials often serves to dismiss the need for controlled experimentation (Stanovich, 2009). Moreover, people may be less motivated to empirically evaluate their folk theories if they already perceive themselves as possessing sufficient information to answer their psychological questions (Verelas, 1996). People often fail to recognize, however, that their understanding of psychological phenomena, no matter how strongly believed, are hypotheses rather than facts that require modification when confronted with new evidence (Kuhn, Garcia-Mila, Zohar, \& Andersen, 1995).

Despite the need for an empirical method to assess psychological phenomena, research has demonstrated that people display a great deal of confidence in themselves as arbiters of knowledge. For instance, Hofer's (2000) study found that undergraduate psychology students believed that firsthand experience in psychology could be regarded as the primary source of 
knowledge. Moreover, participants were more willing to accept a claim that was derived from firsthand experience, even if it conflicted with the research presented in their textbooks. Estes et al. (2003) similarly found that undergraduate students believed that psychology was less amenable to study using the scientific method than biology. As a substitute to empiricism, undergraduates believed that both common sense and personal experiences could be used to answer their psychological questions. Undergraduates also expressed a greater likeliness to change their minds when faced with evidence that contradicted their beliefs in biology than in psychology. Furthermore, they expressed greater confidence in biological experts compared to psychological experts. When explaining why they judged expertise in this manner, participants indicated that it was because psychological phenomena were too complex and variable to be measured using the scientific method. Most notably, nearly $20 \%$ of undergraduates claimed "I just have more confidence in biological science. I don't know why". This demonstrates that people may have difficulties explicitly articulating their beliefs when they stem from an implicit understanding (Keil, 2006).

The belief that psychological topics are not compatible with the scientific method is not unique to undergraduate students. They have been displayed by the general public as well. For instance, one research poll found that $70 \%$ of respondents did not agree with the statement that "psychology attempts to understand the way people behave through scientific research" (Penn, Schoen and Berland Associates, 2008, p. 29). Scientists have similarly expressed a reluctance to believe that psychological phenomena can be investigated in a manner that allows it to adhere to the scientific criterion (Brooks, 2010; Caswell, 2014). For instance, Berezow (2012), a microbiologist argued in a Los Angeles Times article that psychology cannot be regarded as a science because human behaviour is unquantifiable and unpredictable. He claimed that psychologists must resort to arbitrary scales to measure psychological constructs such as 
happiness. Furthermore, he contended that responses on such scales could only be regarded as subjective. Thus, even those that ought to more readily recognize psychology's use of controlled experimentation are not immune to accepting the widely held beliefs that psychological findings are subjective.

It appears the domain dependency of epistemic beliefs, particularly when contrasting those between psychology and other sciences are robust and observable in a multitude of populations. Epistemic beliefs, however, have been found to vary for students majoring in different disciplines. Specifically, students majoring in the hard sciences hold more naïve beliefs about science compared to those in the soft science (Paulsen \& Wells, 1998). For instance, natural science and engineering majors believed that knowledge was more unchanging and certain than humanities and social science majors. Similarly, engineering and business majors have displayed a greater belief in the certainty of knowledge compared to social science and humanity majors, even after controlling for their level of education (Jehng, Johnson, \& Anderson, 1993; Paulsen \& Wells, 1998). For these reasons, some have characterized social science majors as possessing superior epistemic reasoning compared to majors of other disciplines (King \& Kitchner, 1994).

\section{Explicit attitudes of psychology}

A variety of explicit measures has been employed to assess people's conceptions of science and psychology. To more directly assess whether students believe that psychology is a science, the most frequently administered explicit measure has been Friedrich's (1996)

Psychology as a Science Scale (PAS) (Amsel et al., 2011; Bartels, Hinds, Glass, \& Ryan, 2009; Holmes \& Beins, 2009; Pettijohn et al., 2015; Provost et al., 2011). People's psychological interests may be related to the manner that they view the discipline. To that end, 
Leong and Zachar (1991) developed the Scientist-Practitioner Inventory to assess whether psychology students enter the major with a greater desire to conduct scientific research or to become practitioners. Research that has administered these scales simultaneously has found that those with greater scientific interests are more likely to consider psychology to be a science (Holmes \& Beins, 2009).

Psychology as a Science Scale. Friedrich (1996) argued that students of psychology are frequently evaluated on their comprehension of methodology. They are seldom evaluated on their endorsement of their professor's claims, however. The PAS is intended to assess whether students truly endorse their professors' assertion that psychology is a science. The scale is comprised of 15 items that measure the degree that students believe that psychological phenomena are compatible with the scientific method and the degree that they conceptually place psychology in the same category as the hard sciences.

Holmes and Beins (2009) administered the PAS to undergraduate students that were working towards completing their major in psychology at different levels of the curriculum. Specifically, the undergraduates were drawn from introduction to psychology courses, statistics and methods courses, and a three-semester mandatory research course for psychology majors. The results indicated that students enrolled in more advanced psychology courses displayed an increase in scientific literacy and scientific reasoning. Yet, their perceptions that psychology was unscientific remained unchanged. Others found that introductory courses in psychology do little to enhance students' beliefs that psychology is a science (Friedrich, 1996; Pettijohn et al., 2011). Thus, acquiring more sophisticated scientific knowledge does not necessarily lend to an increased belief that psychology is a science.

Sizemore and Lewandowski (2009) similarly demonstrated that students' knowledge about psychology and their attitudes toward the discipline do not necessarily concur. In their 
study, psychology students enrolled in a research methods course were assessed on their attitudes towards statistics and their methodological knowledge at the beginning and end of the course. As was expected, methodological knowledge significantly increased towards the end of the course. Their attitudes towards statistics, however, remained intact. Furthermore, after completing the course, undergraduates saw less value in the utility of statistics. Collectively, these studies demonstrate that course instructions may not help shape student attitudes towards psychology. It is also possible that acquiring knowledge that can explicitly be measured does little to change attitudes that are rooted at an implicit level.

Additional research has contradicted these results, however. For instance, Pettijohn et al. (2011) found a significant increase in PAS scores for students who had completed either a research methods course or a psychology thesis. Similarly, others have found that fourth year psychology majors that had completed more advanced psychology courses displayed higher PAS scores compared to first year undergraduate students (Amsel et al., 2011; Pettijohn et al., 2015). Some courses appear to be more effective in shaping students beliefs than others. Specifically, courses that are geared towards providing students with the knowledge to conduct their own psychological research and put their statistical and methodological knowledge to practical use are more persuasive in convincing students that psychology is a science. This may explain why Friedrich (1996) found no significant differences in PAS scores when comparing students towards the end of an introduction to psychology and the beginning of research methods, but yet found significant increases when they had completed both statistics and research methods courses.

One might reasonably expect psychology majors to be more likely to endorse psychology as a science compared to those majoring in other scientific disciplines. Researchers have obtained mixed results on this front. For instance, some researchers found no significant 
differences in PAS scores among students majoring in psychology, the natural sciences, or education after controlling for the number of psychology courses completed (Bartels, Hinds, Glass, \& Ryan, 2009). Others found, however, that psychology majors displayed greater PAS scores compared to those majoring in business and pedagogy (Morales et al., 2005). Furthermore, pre and post-test differences on the PAS generally appeared to be the greatest for psychology majors compared to non-psychology majors (Pettijohn et al., 2015).

It is possible that students' commitment to the study of psychology may affect their scientific attitudes towards the discipline. To assess this possibility, Amsel et al. (2011) asked undergraduate students both majoring and not majoring in psychology to complete the PAS. Non-psychology majors were additionally asked whether they would contemplate changing their major or minor to psychology. There was a general pattern for psychology majors and potential majors to score higher on the PAS compared to psychology minors and those contemplating a minor in psychology. It was speculated that students that are more invested in studying psychology were more able to conceptualize it as a science because they are more motivated to accept their professors' scientific perspective of psychology. Amsel et al. (2009) conducted a follow up study to test this claim. They asked introduction to psychology students to complete the PAS taking in turn their own perspective and that of their professors. Students' PAS scores were significantly higher when completed from the prospective of their professors. It was suggested that psychology students recognize that psychology is a science, but yet are reluctant to adopt this belief personally.

The PAS has been administered frequently, although not without criticism. When the scale was first developed, Friedrich (1996) claimed that scores were unaffected by social desirability characteristics. More recently, however, Bartels et al. (2009) found evidence to suggest otherwise. In their study, undergraduates completed the PAS as well as a social 
desirability scale to assess their response biases. The results demonstrated that social desirability scores significantly predicted PAS scores. Furthermore, although the majority of the research that has administered the PAS found that students beginning their studies in psychology do not view it as a science, Provost et al. (2011) found evidence to the contrary. In their study, undergraduate psychology students were provided with a checklist of adjectives. They were asked to identify which were associated with psychology and which were associated with science. Based on rank orders, the top four adjectives associated with science (i.e., complex, logical, structured, and interesting) were amongst the top six adjectives that were associated with psychology. Considering the alternative conclusions that have been reached as a result of the tools researchers employ and the potential for response biases in explicit measures, the use of implicit methods has the potential to more accurately evaluate students' perceptions of psychology.

Scientist-Practitioner Inventory. Another frequently used explicit measure to assess people's image of psychology has been Leong and Zachar's (1991) Scientist-Practitioner Inventory (SPI). The inventory is comprised of 42 items that assess whether students hold greater scientific interests (e.g., developing new explanations of well-accepted empirical studies) or practitioner interests (e.g., conducting a psychotherapy session with an individual client). Research found that scientific and practitioner interests are correlated for first year undergraduates, but are negatively correlated for fourth year psychology majors and psychology graduate students (Holmes \& Beins, 2009; Leong, Conant, \& Zachar, 2004; Manning, Zachar, Ray, \& LoBello, 2006; Zachar \& Leong, 1992). Thus, as students progress in their psychology studies, they become more polarized in their psychological interests. 
Some researchers have administered the PAS and SPI in tandem to assess whether the propensity to view psychology as a science is related to students' psychological interests. For instance, Holmes and Beins (2009) administered both scales to psychology majors. Generally, students reported greater interests in practitioner activities compared to scientific ones. Most importantly, the results revealed that students with greater scientific interests were more likely to perceive psychology as a science. In contrast, only a minority of students with greater practitioner interests displayed higher PAS scores. In a similar study, Manning, Zachar, Ray, and LoBello (2006) administered the SPI to psychology students both prior and after completing a research methods course. Generally, students displayed greater interests in practitioner opposed to scientific activities. Their results showed that after taking a research methods course, students displayed a loss of interests in scientific activities. Unexpectedly, research method students similarly displayed a loss of interests in practitioner activities as well. Thus, a course that is aimed to equip students with the necessary tools to become successful scientists generated a loss of interest in psychology. Some have speculated that interests in practitioner activities may entice students to begin a major in psychology (Gervasio, Wendorf, \& Yoder, 2010). They may lose interest, however, after realizing that the psychology curriculum is geared towards providing them with an understanding of science.

Consequently, many have called for educating the public on what psychologists do given people's misrepresentation of the profession (Rosenthal, McKnight \& Price, 2001; Webb \& Speer, 1985). For instance, people generally confuse the roles of psychologist and psychiatrist (Dempsey, 2007; Janda et al., 1998; Murstein \& Fontain, 1993; Von Sydow \& Reimer, 1998). Moreover, undergraduates displayed a tendency to overestimate the percentage of psychologists 
that are employed as therapists or counsellors (Rosenthal, McKnight \& Price, 2001). To that end, researchers that have asked students to draw a typical psychologist have in large found that they depict psychologists more narrowly in clinical roles (Barrow, 2000; Hartwig, 2003). What is problematic about these findings is when people overestimate the number of psychologists that are practitioners and they underestimate those that are engaged in scientific research (Lilienfeld, 2012).

\section{Implicit attitudes of science}

Considering the research presented thus far, it can readily be seen that researchers have primarily explored people's conceptions of psychology and science explicitly. However, to understand psychology's associations with people's concept of science, it is relevant to recognize the cognitive mechanisms that are in operation when concepts become activated, how this activation influences explicit responses and behaviours, and ultimately, the methods most suitable to study these concepts. While explicit attitudes are the result of thoughtful and deliberate consideration, implicit attitudes are automatically activated (Fazio et al., 1995). Some postulate that this automaticity occurs without an individual's conscious awareness (Banaji, Lemm, \& Carpenter, 2001). Others contend that people can exercise a certain degree of cognitive control during tasks that are intended to measure automatic processes, however (Fazio et al., 2003; Gonsalkorale, Allen, Sherman, \& Klauer, 2010). In either case, when activated, concepts can influence how one processes, encodes, and organizes information (Markus \& Zajonc, 1985).

Building on these assumptions, various techniques have been developed to measure the activation of people's attitudes and concepts. The most recognized of these measures has undoubtedly been Greenwald, McGhee, and Schwartz's (1998) Implicit Attitude Test (IAT). 
The IAT measures the relative strength of association between concepts. Typically, this procedure requires participants to respond to a variety of stimuli pertaining to a target category in relation to bipolar attributes. For instance, if one wanted to determine the degree to which a sample displays implicit sexist attitudes, the participants might be asked to respond to "woman" paired with "smart" or "dumb". If the pairing of woman with negative adjectives leads to faster reaction times than with positive ones, then this semantic priming suggests that a sexist attitude indeed exists. Moreover, note that the participants are not directly asked if they hold such a belief. Rather, they display it through their behavior in the experiment without realizing it. This task and several similar approaches (Fazio \& Olson, 2003) are implicit measures. For example, Nosek and Banaji’s (2001) Go/No-Go Task (GNAT) requires participants to categorize stimuli. Participants are asked to do so by responding with only one response key when the stimuli reflect concepts of interest and are required to refrain from providing any response otherwise. Implicit measures are particularly valuable in measuring concepts that are more automatically activated as they prevent participants from exercising cognitive control in deliberating about their responses. In doing so, they greatly minimize response biases and social desirability (Cvenek, 2011; Fazio \& Olson, 2003; Nosek et al., 2002). Moreover, they can measure associations that people have acquired but not readily recognized. For these reasons, researchers have found evidence to suggest that when examining people's endorsement of certain attitudes, explicit and implicit measures are typically uncorrelated (Fazio et al., 1995; Greenwald et al., 1998) although this is not always true (See Fazio et al., 2003; Nosek et al., 2002). The correspondence between the two measures are dependent on context (Wittenbrink, Judd, \& Park, 2001), the initial strength and awareness of one's implicit attitude (Fazio \& Olson, 2003), as well as the accessibility of one's implicit attitudes (Wilson, Lindsey, \& Schooler, 2000). Fazio's (1990) Motivation and Opportunity as Determinants Model (MODE) posits that the degree to 
which implicit and explicit measures coincide is dependent on the degree that people are motivated and have the opportunity to deliberately reflect on their explicit responses. Specifically, some are more motivated to retrieve their explicit attitudes towards a particular social category or issue. For these individuals, responses on explicit measures are presumed to be less correlated with implicit ones. In comparison, others may have yet to develop an explicit attitude towards a social category or lack in the motivation to retreive this explicit attitude. For these individuals, implicit and explicit measures are more likely to be correlated (Koole Dijksterhuis, \& van Knippenberg, 2001).

More recently, researchers have begun to adopt implicit measures to assess the degree to which people's academic gender stereotypes accounts for explicit attitudes towards science. Specifically, such research has attempted to measure people's stereotypes that science is a male's domain. This research has found that at an implicit level, people hold stronger male-science associations than male-humanities associations (Lane, Goh, \& Driver-Linn, 2012). Furthermore, people hold stronger male-math (Gilbert, O’Brien, Garcia, \& Marx, 2015), and male-physics associations (Kessel, Rau, \& Hannover, 2006) than male-English associations. Nosek et al.'s (2009) study found that countries that more strongly displayed these academic gender stereotypes were more likely to exhibit greater gender gaps in standardized performance in the mathematics and sciences. What is more, academic gender stereotypes have been found to account for students' academic plans to pursue science (Lane, Goh, \& Driver-Linn, 2012). Women that more strongly considered the humanities to be a woman's domain were more likely to indicate a disinterest in pursuing the sciences.

It appears these academic gender stereotypes might be difficult to change considering the automaticity of stereotypes and the young age they are acquired (Cvencek, Meltzoff, \& 
Greenwald, 2011). Research has demonstrated, however, that implicit attitudes are more malleable than one might expect (Blair et al., 2001; Dasgupta \& Greenwald, 2001). For instance, Kessels et al. (2006) found that the implicit stereotype that physics was a heteronomous discipline (i.e., one where creative and self-determined behavior is discouraged) could be manipulated. This was demonstrated by asking participants to read either a passage drawn from a typical physics textbook or an article that emphasized the creative aspects of science drawing from examples in physics. Participants subsequently completed an IAT to assess physicsheteronomy associations. The results revealed that reading the article that emphasized creativity weakened the physics-heteronomy association for participants who had taken a physics course during the last year of high school. Thus, implicit attitudes can be manipulated even after reading a brief article that contradicts one's beliefs. It may be reasonable to expect, then, that greater exposure and experience with an academic discipline can also change implicit attitudes.

Kessels et al.'s (2006) study also assessed the physics-male and physics-difficult associations. As expected, psychology students associated physics with males and difficulty. Their study also exemplified the need to broaden the scope of the scientific attitudes being measured. For instance, they sought out to determine whether implicit associations could predict explicit attitudes towards the sciences. They found that $25 \%$ of the variance in explicit attitudes could be accounted for by implicit gender attitudes alone while heteronomy and difficulty explained an additional $15 \%$ of the variance. However, to measure any additional attitude, researchers must administer an additional IAT to participants. For instance, Kessel et al.'s study required participants to complete three separate IAT's: one for the physics-male associations, a second for the physics-difficult associations, and a third for the physics-heteronomy associations. Multiple IATs within a given experiment place greater cognitive demands on participants because they must change the decisional criterion for each test. This also lengthens the amount 
of time required to complete the task thereby increasingly the likelihood that participant will experience fatigue and boredom. In contrast, Meyer and Schvaneveldt's (1971) lexical decision task (LDT) remedies these shortcomings while maintaining the ability to measure multiple associations within a single task.

Lexical Decision Task. In this procedure, participants are simultaneously presented with a pair of string of letters. The letter strings can be comprised of either real words or non-words. Therefore, the trials can consist of a pair of words, a pair of non-words, or a pair consisting of a word and a non-word. Participants are asked to respond with one key if the pair consists of real words and another otherwise. Due to its nature, the LDT is a lexical rather than a semantic task (Fischler, 1977). Thus, participants are not required to directly reflect on the words' meanings or their degree of association. Nonetheless, accumulated evidence has found that people take less time and are more accurate in determining whether the pairs are both words when they are associated (Besche-Richard, Passerieux, \& Hardy-Bayle, 2005; Dannenbring \& Briand, 1982; Moss, Ostrin, Tyler, \& Marslen-Wilson, 1995; Schaeffer \& Wallace, 1969). Thus, both latency and error rates in making lexical decisions are taken as measures of implicit association (Fazio \& Olsen, 2003). This has been attributed to the fact that words which are more closely associated in memory facilitate their retrieval and are accessed with greater ease (Collins \& Quillan, 1970). Although this facilitation is greater for pairs that are associatively related (i.e., doctor-nurse) based on free association norms, research has also demonstrated that lexical decisions are quicker for word pairs that are semantically related, but not associatively related. That is, some words may be judged as highly related on semantic scales despite not eliciting one another during free association tasks (e.g., wife-nurse) (Fishcler, 1977).

Traditionally, the LDT adopts a dual-response technique whereby one key is assigned to word pair trials and another is assigned to the other possibilities. However, this methodology 
can lead to inaccurate responses because participants may momentarily forget the positions of the response keys despite correctly classifying the letter strings as a word or non-word (Perea, Rosa, \& Gomez, 2002). To remedy this problem, many have advocated for a single response key technique (Gordon, 1983). The resulting go/no-go LDT requires participants to only respond if the pairs are both words and to refrain from providing any response if at least one in the pair is a non-word. By minimizing the cognitive demands in the task, the go/no-go LDT has been found to produce both fewer number of errors and quicker reaction times than the traditional yes/no LDT (Perea, Rosa, \& Gomez, 2002). The former benefit is particularly advantageous given trials in which participants exhibit an incorrect response are not of interest.

\section{Need for an implicit measure}

Considering the many benefits of employing an implicit measure, it is surprising that researchers have continued to pursue predominantly explicit measures to assess psychology’s scientific status. Although there are many ubiquitous benefits to implicit measures, there are three that are particularly relevant when investigating people's image of psychology. The first is related to the fact that researchers have inconsistently characterized undergraduate students' perceptions of psychology as a result of employing alternative forms of explicit measures. For instance, more direct measures have found that undergraduates perceive psychology to be less scientific and less important than ones less direct (Hartwig \& Delin, 2003; Provost et al., 2011; Webb, 1986).

Secondly, research has demonstrated that undergraduate students are more likely to explicitly endorse psychology as a science after they have completed a greater amount of psychology coursework (Amsel et al., 2011; Pettijohn et al., 2015). However, by more narrowly adopting explicit measures, researchers have neglected to consider whether this change in explicit responses can similarly be observed at an implicit level. Petty et al.'s (2006) Past 
Attitudes are Still There (PAST) model posits that people may appear to have abandoned old attitudes that implicitly remain intact and continue to influence behaviours. For that reason, some have argued that researchers may exaggerate the degree to which people display a shift in attitudes when solely considering explicit measures (Wilson et al., 2000). Drawing upon this possibility, upper year undergraduate students may display a shift in explicit attitudes because they are more motivated to respond in socially desirable ways. Correspondingly, a third reason why an implicit measure is suitable rests in the fact that the most frequently used explicit measures to assess students' endorsements of psychology as a science, the PAS has been found to be prone to social desirability (Bartels, Hinds, Glass, \& Ryan, 2009).

\section{Summary}

In sum, many elements that appear to be incorporated in people's concept of science have little to do with an empirical approach towards understanding phenomena. For instance, one factor people seem to consider when classifying a science is its topic of study (Krull \& Silvera, 2013). The topics investigated in the hard sciences seem to better fit people's overall concept of science compared to psychological topics. Furthermore, people's concept of science appears to be dominated by specific characteristics, such as difficulty and importance. Psychology is characterized as easy and less important, however (Hartwig \& Delin, 2003; Janda et al., 1998; Keil et al., 2010; Plagianakos, 2015). Finally, knowledge derived from scientific research is associated with a connotation of certainty, whereas knowledge within psychology is regarded as intuitive (Estes et al., 2003; Hofer, 2000). Evidently, people's image of science does not resemble that of psychology. Given the automaticity to which these concepts may be activated, an implicit measure may lead to a more comprehensive understanding of why psychology is not considered to be a science. 


\section{Present study}

Extending beyond the extant literature, the purpose of the present study is to examine students' scientific attitudes towards psychology at the implicit level. To achieve this goal, I will adopt a go/no-go lexical decision task. Stimuli were selected to represent a variety of scientific and psychological features. These include scientific disciplines, their topics of study, and methodological terminology. Furthermore, words that are more exclusively associated with science and psychology, and that more closely capture people's concepts of these categories will be included. A go/no-go LDT will reveal the strengths of these associations. This will be achieved by comparing the relative ease to which undergraduates can make lexical decisions for pairs that comprise of psychology, science, scientific disciplines, and the terminology that reflects methodology and elements irrelevant to methods.

A secondary purpose of this experiment is to compare the implicit and explicit measures of psychology's image as a science. As explicit measures, both Friedrich's (1996) Psychology as a science Scale and Leong and Zachar's (1993) Scientist-Practitioner Inventory will be employed. These scales will determine whether the explicitly reported perceptions of psychology correspond with students' implicit attitudes as measured by reaction times. Moreover, it can be determined whether psychological interests can predict implicit attitudes towards the discipline.

Finally, the experiment will explore whether psychology's implicit associations with science changes over time. This will be achieved by sampling both first year psychology students as well as upper year psychology students. The latter group of students more committed to the study of psychology, with additional years of experience and exposure to the field, have demonstrated a shift in explicit attitudes (Amsel et al., 2009; Friedrich, 1996; Pettijohn et al., 
2011). This experiment will be able to determine whether this change can be observed similarly at an implicit level.

\section{Hypotheses}

The analyses will focus on psychology's implicit associations with science as well as how these implicit associations may change over time. It is hypothesized participants will display quicker reaction times when "science" is paired with other scientific disciplines relative to when "science" is paired with "psychology. This difference in response latency is hypothesized to be larger for first year undergraduates than upper year psychology students. It is also predicted that participants will display shorter reaction times when "science" and scientific disciplines are paired with methodological terminology relative to when "psychology" is paired with methodological terminology. It is predicted that upper year psychology students will display shorter reaction times when both psychology is paired with methodological terminology compared to first year undergraduates.

Furthermore, it is predicted that participants will display shorter reaction times when "science" and other scientific disciplines are paired with terminology that denote people's conceptions of science relative to when "psychology" is paired with these terms. Specifically, it is hypothesized that participants will display quicker RTs when science and hard science disciplines are paired with "difficult", "important", and "fact" compared to when presented with "psychology". First year undergraduates are predicted to display shorter reaction times for these pairings than upper year psychology students. Conversely, it is predicted that shorter reaction times will be found when "psychology" is paired with words that reflect its currently held image compared to when "science" and scientific disciplines are paired with these words. Specifically, it is hypothesized that participants will be quicker to respond to "psychology" when it is paired with "easy", "useless", and "subjective" compared to when science and hard science disciplines 
are presented with these terms. First year undergraduates are predicted to display shorter reaction times for these pairings than upper year psychology students.

The next set of hypotheses is related to the explicit measures. Consistent with past research, it is hypothesized that upper year psychology students will explicitly report higher beliefs that psychology is a science than first year undergraduates based on their PAS scores (Amsel et al., 2011; Friedrich, 1996; Pettijohn et al., 2011). Moreover, consistent with previous findings, it is predicted that first year psychology students will possess greater practitioner interests compared to scientific ones (Holmes \& Beins, 2009; Manning, Zachar, Ray, \& LoBello, 2006). Furthermore, those with greater scientific interests are hypothesized to display higher PAS scores compared to those that indicate greater practitioner interests.

The last set of predictions is concerned with the correspondence between the implicit and explicit measures. Drawing upon Fazio's (1990) MODE model, it is hypothesized that upper year psychology students will have greater motivation to deliberate on their explicit responses. Thus, these students are predicted to display a weaker relationship between their explicit and implicit responses. First year undergraduates, in contrast, are predicted to have less opportunity and motivation to reflect deliberately on their beliefs of psychology as a science.

Correspondingly, while completing the explicit measures they are predicted to behave in a less motivated manner and display a greater correspondence between their implicit and explicit measures.

\section{Method}

\section{Participants}

One hundred and fifteen Carleton University students participated in the study. Sixtynine participants were recruited from introduction to psychology courses and received course credit in exchange for their participation. Given that these courses are open to students from a 
variety of academic backgrounds, only nine were psychology majors. The remaining introduction to psychology students were either majoring in a soft science $(n=28)$, a hard science $(n=15)$, in unrelated fields $(n=22)$, or had yet to declare a major $(n=4)$. The remaining 46 participants were recruited from third or fourth year psychology classes that included the honours thesis course, the project seminar course, an upper-level statistics course, and a third year seminar course. Within this group, 36 participants were majoring in psychology. The remaining upper year students were either majoring in a soft science other than psychology ( $n=41)$, a hard science $(n=2)$, or unrelated discipline $(n=2)$. One participant did not disclose this information. Participants that completed the study during the regular school semesters received $\$ 10$ for their participation while those who participated during the summer semester were compensated with $\$ 20$. This increase was implemented to facilitate recruitment.

\section{Measures}

Go/no-Go Lexical Decision task. The stimulus set comprised of 22 English words and 22 non-words. Each word in the task was paired with each other generating 231 "go" trials for the go/no-go lexical decision task. An equal number of no-go trials were generated by using one word, and one of the 22 non-words that were selected at random without replacement. Each participant completed a total of 462 experimental trials.

All of the 22 English words used in the task are presented in Table 1. Five of these comprised of scientific disciplines including psychology, the hard sciences (e.g., biology, chemistry, and physics) as well as neuroscience given its status as the most prestigious science (Fernandez-Duque et al., 2015; Hopkins, Weisberg, \& Taylor, 2016). Finally, the inclusion of the superordinate "science" allowed for an assessment of its associative strength for the selected scientific disciplines. 
Table 1

List of word stimuli.

\begin{tabular}{lll}
\hline Disciplines & Subject Matter & Methodological Terminology \\
\hline Psychology & Behaviour & Analysis \\
Physics & Gravity & Experiment \\
Chemistry & Chemical & Hypothesis \\
Biology & Animal & Observation \\
Neuroscience & Brain & \\
Science & Mind & \\
& & \\
Scientific words & Psychological words & \\
\hline Difficult & Easy & \\
Important & Useless & \\
Fact & Subjective & \\
\hline
\end{tabular}

An additional six words were included to reflect subject matter the disciplines study and were drawn from Morgan's (2017) free association study. Specifically, the top associates for each scientific discipline that also reflected a topic of investigation was selected. It should be noted that the "brain" and "mind" were associates of both neuroscience and psychology. Thus, "behaviour" was also included to ensure that a topic uniquely associatively related with psychology was incorporated (the forward cue-to-target strength for these words are given in Appendix A). Next, four words reflected methodological terminology. Finally, the remaining words were intended to display the characteristics that are considered to be denotive of science (i.e., “difficult”, “important”, "fact”) and psychology (i.e., “easy”, “useless”, “subjective”).

An additional 22 pronounceable non-word stimuli (presented in Table 2) were created to generate the no-go trials. Non-words were produced by obtaining 22 real words that matched our word stimulus set as closely as possible with respect to word length and frequency (words from which non-words were generated are shown in Appendix B). They were transformed into 
non-words by alternating the interior letters, while ensuring both the first and last letters of the words remain unchanged.

Table 2

List of Non-Words.

\begin{tabular}{ll}
\hline Word & Non-word \\
\hline analysis & miltuple \\
animal & guatir \\
behavior & dastince \\
biology & sagnils \\
brain & gevis \\
chemical & degisted \\
chemistry & indacites \\
difficult & ganerelly \\
easy & sopt \\
experiment & contrubite \\
fact & slod \\
gravity & sanetor \\
hypothesis & weadsprid \\
important & tachnicel \\
mind & knid \\
neuroscience & mesinterprit \\
observation & cummonities \\
physics & ragerds \\
psychology & parchusing \\
science & stertad \\
subjective & oblagition \\
useless & chergad \\
\hline
\end{tabular}

The procedure was based largely on Perea et al.'s study (2002; See also Hino \& Lupker, 2000) and is shown in Figure 1. E-Prime 2.0 software was used to present the stimuli and record reaction times (Psychology Software Tools, Pittsburgh, PA). On each trial, participants were presented with a word/word pair, a non-word/non-word pair, or a word/non-word pair. They were instructed to press the "m" key using their dominant hand if the pair consisted of two words and to refrain from providing any response when at least one of the strings was a non-word. 
They were asked to do so as quickly as possible while maximizing accuracy. Prior to completing the experimental trials, participants completed two blocks of twenty practice trials to familiarize themselves with the task. The stimuli for the practice trials consisted of a variety of fruits (words and non-words for practice trials presented in Appendix C). Only during these trials were participants provided with feedback with respect to their accuracy.

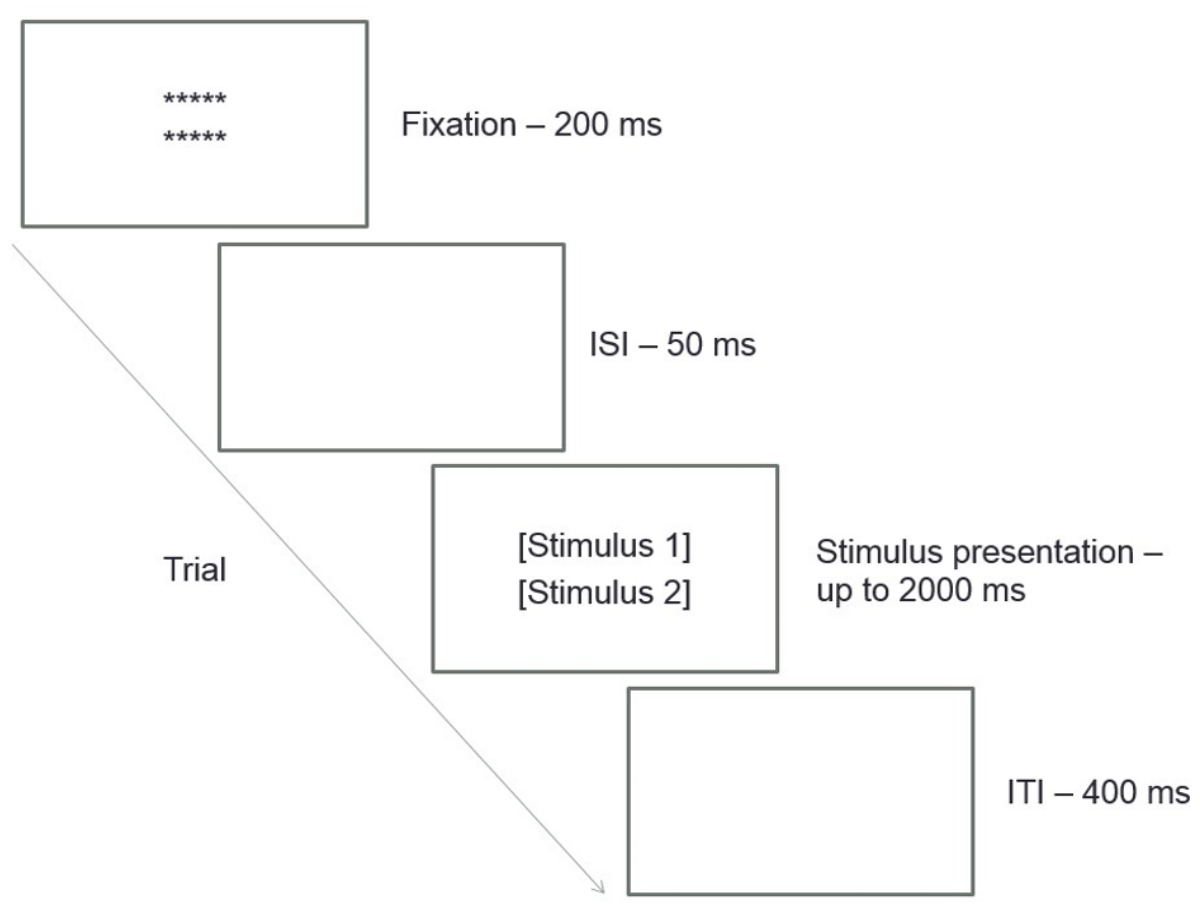

Figure 1. The procedure for the go/no-go lexical decision task. A modified Go/No-Go lexical decision task procedure taken from Perea et al. (2002). Participants responded "Go" with dominant hand. The stimuli remained on screen until the participants responded or when 2000 ms had elapsed.

Subsequently, each participant received a total of 462 experimental trials. Half of these were critical trials for which a go response was expected, whereas the other half of the trials required no response. Each trial began with a fixation point of two rows of asterisks presented one on top of the other in Calibri 32-point font. They remained on screen for $200 \mathrm{~ms}$ followed by an inter-stimulus interval of $50 \mathrm{~ms}$. Next, the letter strings were presented one on top of the 
other. The pair remained on screen until the participant had made a response or until $2000 \mathrm{~ms}$ had elapsed. The inter-trial interval lasted $400 \mathrm{~ms}$.

The placement of the letter strings was counterbalanced across participants, such that any given participant may have been presented with "psychology" above "science" or "psychology" below "science". Participants never received both these combinations. Each word and non-word was presented to participants an equal number of times to avoid frequency effects within the task. The order of the trial presentation was randomized across participants. Participants were given the opportunity to take self-paced breaks after completing a set of 115 trials.

Psychology as Science Questionnaire. Freidrich's (1996) PAS questionnaire is comprised of 15 items as well as 5 filler items and is intended to measure the degree to which psychology is a regarded as science (PAS items are presented in Appendix D). Participants were asked to indicate their agreement with each item using a 7-point Likert-scale ranging from 1 (strongly disagree) to 7 (strongly agree). The 15 items load on to three factors. Factor one assesses the degree to which people conceptually place psychology in the same category as the hard sciences (e.g., "It's just as important for psychology students to do experiments as it is for students in chemistry or biology"). The second factor assesses people's endorsement of the necessity of methodological training in psychology (e.g., "Courses in psychology place too much emphasis on research and experimentation"). Finally, the third factor is related to people's understanding about the nature of knowledge in psychology (e.g., "Psychology will never be a true science because its predictions about individual behaviour are seldom exact or certain"). Scientist-Practitioner Inventory. Leong and Zachar's (1991) brief version A of the Scientist-Practitioner Inventory was employed. It is presented in Appendix E. It consists of 18 
items, nine of which assess greater interest in practitioner activities (e.g., "Conducting couples and family therapy") while the other nine assess greater interest in scientific activities (e.g., “Collecting data on a research project you designed"). This shortened version eliminates items redundancy and displays similar psychometric properties (including test-retest reliability and concurrent validity) to the original 42-item inventory (Leong \& Zachar, 1993). Participants are asked to indicate their level of interest in these activities on a 5-point Likert-scale ranging from 1 (very low interest) to 5 (very high interest). The Cronbach alpha obtained for the scientist and practitioners interests were .89 and .88 , respectively.

\section{General Procedure}

Participants were tested individually in a quiet room where they were seated approximately $60 \mathrm{~cm}$ away from a 14-inch computer monitor. They were informed that the experiment would require them to distinguish real words from non-words and that the words would comprise of academic words and features. After providing the informed consent, the participants first completed the go/no-go LDT. Next, they answered the PAS and SPI. Then, participants were asked "Is psychology a science?" and "Are you majoring in a scientific discipline?" Finally, they provided some demographic information. In total, participants completed the experiment in approximately 45 minutes.

\section{Results}

\section{Go/no-go LDT Response time analyses}

Data Cleaning. Participants' compliance with the go/no-go LTD was assessed prior to analyzing the data. Typically, participants that display error rates greater than $10 \%$ are excluded from the analyses (Moss, Ostrin, Tyler, \& Marslen-Wilson, 1995; Thomas, Neely, \& O’Connor, 2012). A threshold of $11 \%$ was used in the present experiment, thus eliminating nine 
participants. Two additional participants were excluded from all analyses: one for indicating non-native fluency in English and one for showing prior knowledge of the experimental goals. Accuracy across all 462 trials were nearly identical for first year $(M=96 \%, S D=.029)$ and upper year students $(M=95 \%, S D=.03), t(113)=.60, p=.55$.

Further alterations were made to individual reaction times. Specifically, $.019 \%$ of trials were erroneous and therefore excluded from the analyses. Moreover, $.045 \%$ of RTs that were less than 250 ms or greater than 1500 ms were eliminated (Hino \& Lupker, 2000; Perea, Rosa, \& Gomez, 2002). Finally, .01\% of RTs fell beyond 2.5 standard deviations from the mean. These responses were considered outliers and were Windsorized (Van Selst, \& Jolicoeur, 1994). One participant was excluded from analyses on the PAS scale for displaying string responding.

Correcting Reaction times to account for lexical processing effects. It is well understood that a variety of lexical characteristics can affect the speed at which words are recognized (Balota \& Chumbley, 1984; Hino \& Lupker, 2000; Schvaneveldt \& Meyer, 1973; Segui et al., 1982). The words used in the present experiment exhibited a range of lexical properties as shown in Appendix F. To exclude the possibility that the effects found in the response time analyses were due to these differences rather than the strength of association between the word pairs, they were adjusted.

A word frequency adjustment made use of the Subtlexus' database which contains the prevalence of over 50 million English words (Brysbaert \& New, 2009). Using this database, the frequency count for each of the 22 words used in the experiment was obtained. Then, the frequency counts for each word-word pair in the task were summed. For example, "science" has a frequency of 1900 and "psychology" has a frequency count of 279. Thus, the summed frequency for the "psychology-science" pair was 2179. In comparison, "neuroscience" has a much lower frequency count of 2, resulting in a summed frequency count of 1902 for the 
"science-neuroscience" pair. Thus, one might expect the "science-neuroscience" pair to be responded to slower than the "psychology-science" pair given that the latter exhibits a much lower summed frequency count. To control for such effects, the frequency sums were partialled out from participants raw RTs. The resulting residual represent the strength of association between the word-word pair supposing that their frequency counts were constant. Thus, the magnitude of a positive residual would indicate the degree to which two words were implicitly associated above and beyond what frequency effects could account for. In contrast, a negative residual would indicate that time to respond to the pair was even slower than one might expect given their frequencies.

Following the data cleaning procedure, all response time analyses were conducted using the uncorrected RTs and the RT corrected for frequency. The results of the analyses involving the corrected RTs will only be presented when they lead to different results than the uncorrected ones. Finally, when Maulchy's test of sphericity was violated for any of the RT analyses, the Greenhouse-Geisser correction was used.

Science with disciplines. To determine whether "psychology" and the other scientific disciplines (biology, chemistry, physics, and neuroscience) were differentially associated with "science" and whether such associations differed between first year and upper year students, a 2 (group: first years vs. upper years) x 5 (discipline: psychology, biology, chemistry, physics, and neuroscience) Mixed-Design ANOVA was conducted. The results are shown in Figure 2. The main effect of group was not significant, $F(1,87)=.33, p=.56$, partial $\eta^{2}=.004$. The main effect of discipline was found to be significant, however, $F(4,348)=9.07, p<.001$, partial $\eta^{2}=$ .094. Finally, the interaction between year of study and discipline was found to be marginally significant, $F(4,348)=2.49, p=.051$, partial $\eta^{2}=.028$. Importantly, however, after correcting 
the RTs for word frequency, this interaction became significant, $F(4,396)=2.68, p=.037$, partial $\eta^{2}=.026$.

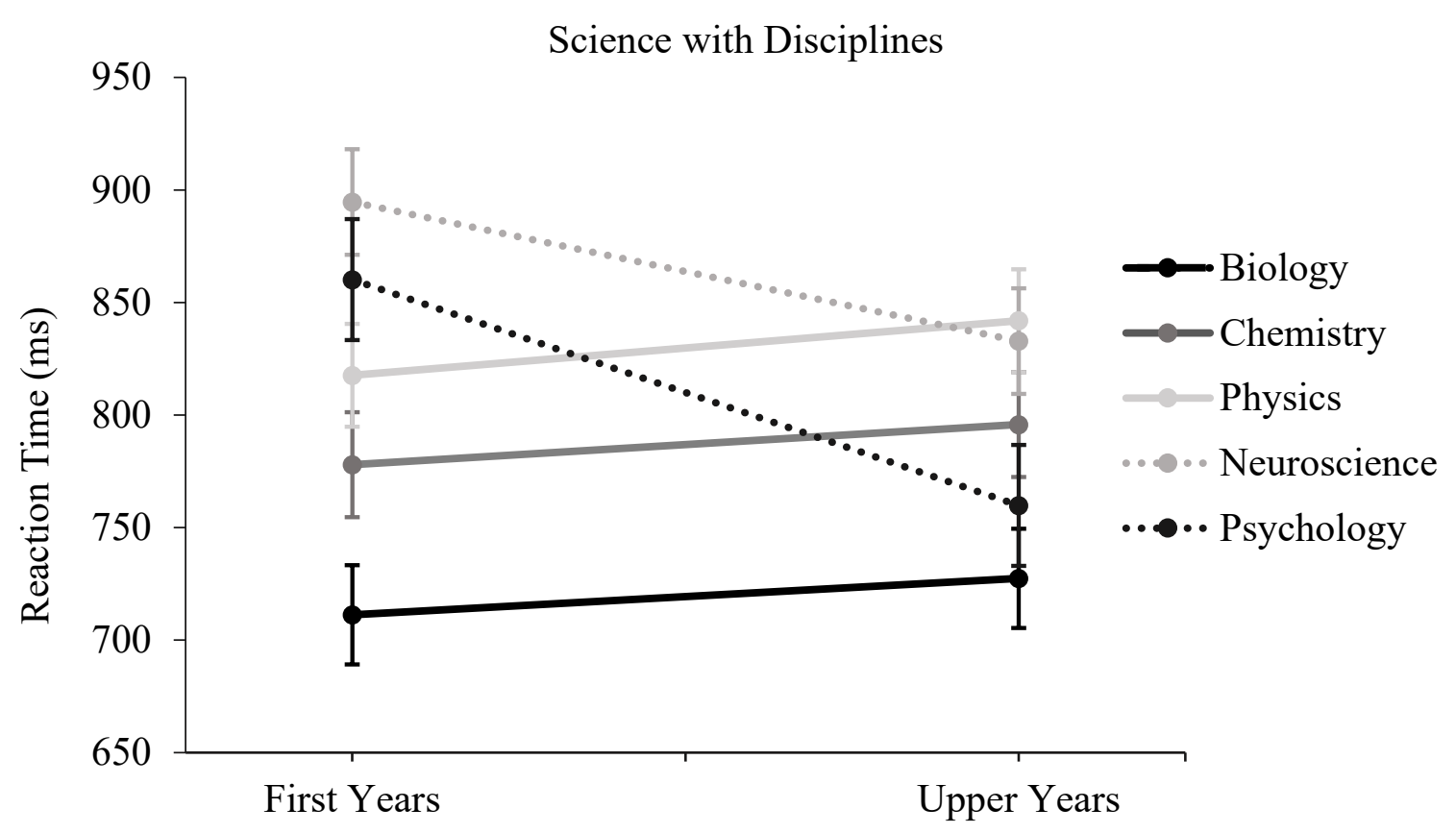

Figure 2. "Science" with disciplines. Error bars represent the standard error.

As illustrated in Figure 2, upper year students were considerably quicker at responding to "psychology-science" compared to first year students. The analysis of simple main effects conducted on the uncorrected RTs did not find this difference to be significant $(M D=100.34, S E$ $=54.01, p=.067)$. However, the RTs correcting for word frequency found this difference to be significant, $(M D=.107, S E=.048, p=.029)$. Thus, after adjusting for lexical processing effects, psychology's implicit associations with science appears to improve with greater exposure to the psychology curriculum. No other "science-discipline" pair demonstrated significant differences in RTs between years of study. Furthermore, considering participants as a whole, "science" was responded to the quickest when presented with "biology" $(M=719.32, S E$ $=22.57)$ followed by "chemistry" $(M=786.85, S E=23.86)$, "psychology" $(M=810.00, S E=$ 
27.00), "physics", $(M=829.77, S E=23.36)$, and finally "neuroscience" $(M=863.74, S E=$ 23.79). Although this order somewhat varied depending on participants' year of study, biology was the most implicitly associated with science for both groups of students.

Finally, the effects of stimuli positioning on RTs were examined. An independent samples $t$-test revealed no significant differences in RTs between first and upper year students when "science" was presented above "psychology", $t(47)=.90, p=.373$. Upper year students, however, displayed a significant RT advantage when "psychology" was presented above "science", $t(48)=2.18, p=.034, M D=152.49, S E=69.96$. These results may suggest that "psychology" is more effective at priming "science" for upper year students.

Methodological Terminology. The next set of analyses were concerned with assessing the degree to which "psychology" was associated with methodological terminology relative to "science" and the other science disciplines. To that end, an average RT was calculated that included "psychology" when paired with "experiment", "hypothesis", "observation", and "analysis". Similarly, an average was calculated for "science" when paired with these terms. Finally, the average for "biology", "chemistry", "physics", and "neuroscience" when paired with these terms was also calculated. A 2 (group: first years vs. upper years) x3 (methods with: psychology, science, the hard sciences) Mixed-Design ANOVA was conducted to determine whether first year and upper year students differentially associated method terms with these disciplines. The results are shown in Figure 3. 


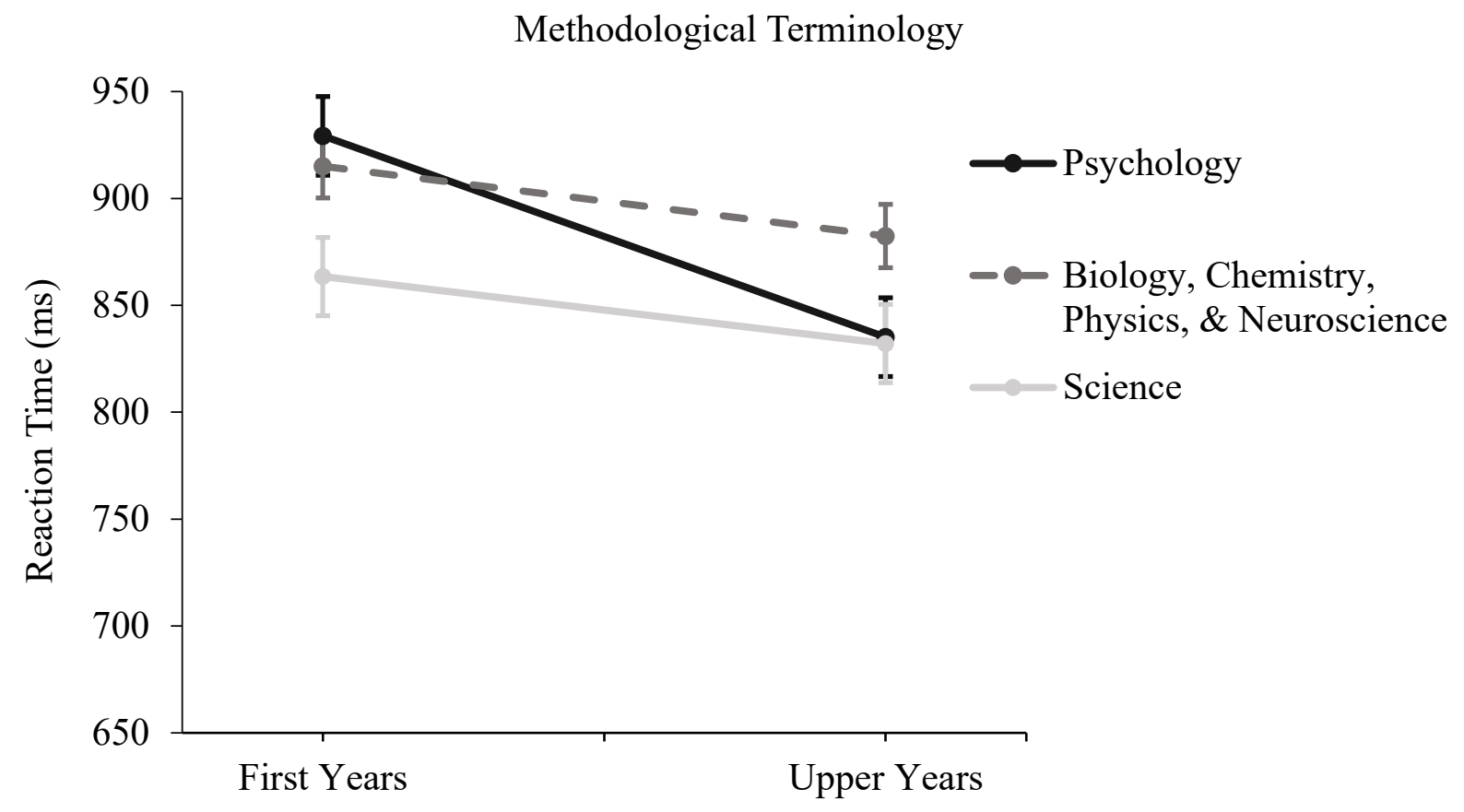

Figure 3. Methodological Terminology. Error bars represent the standard error.

The results demonstrated a significant main effect of discipline whereby participants as a whole were quickest to respond to methodological terminology when paired with "science", followed by "psychology", and then the hard sciences, $F(2,202)=8.11, p=.001$, partial $\eta^{2}=$ .074. Furthermore, the main effect between groups demonstrated no significant differences in RTs between first year and upper year students, $F(1,101)=2.81, p=.097$, partial $\eta^{2}=.027$. The interaction between year of study and methodological terminology was significant, however, indicating that first and upper year students did not equally associate methodological terminology with the discipline groups, $F(2,202)=3.87, p=.03$, partial $\eta^{2}=.037$.

As illustrated in Figure 3, the relatively flat lines when "science" or the hard sciences were paired with methodological terminology indicate that these implicit associations remain relatively stable between first and upper year students. In fact, the only meaningful difference between groups appears to be with respect to "psychology". Specifically, the simple main effect 
demonstrated that upper year students were significantly quicker to respond to methodological terminology when it was paired with "psychology" compared to first year students, $(M D=94.15$, $S E=36.49, p=.011)$. The other simple main effect were not significant $(p>.28)$. Thus, students who had already completed research methods courses and were currently enrolled or completed advanced statistics more strongly associated psychology with an empirical approach, even at an implicit level.

Conceptions of Science. The following analysis aimed to explore the degree to which "psychology" and "science" were associated with words more commonly denotative of science. Thus, an average RT where "science" and "psychology" were paired with "difficult", “important", and "fact" was calculated for each participant. A 2 (group: first year vs. upper year) x 2 (discipline: science vs. psychology) Mixed-Design ANOVA was conducted to explore potential differences in RTs between these pairings for first and upper year students. These results are presented in Figure 4. There was no main effect for year of study, $F(1,102)=1.26, p$ $=.56$, partial $\eta^{2}=.01$. The main effect of pair, however, was significant $F(1,102)=4.82, p=$ .03 , partial $\eta^{2}=.05$. Specifically, RTs were significantly quicker when these scientific terms were paired with "science" $(M=810.32, S E=16.79)$ compared to "psychology" $(M=847.99$, $S E=20.69), F(1,102)=4.82, p=.03$, partial $\eta^{2}=.05$. Moreover, the interaction between year of study and word-pair was significant, $F(1,102)=4.11, p=.045$, partial $\eta^{2}=.04$. 


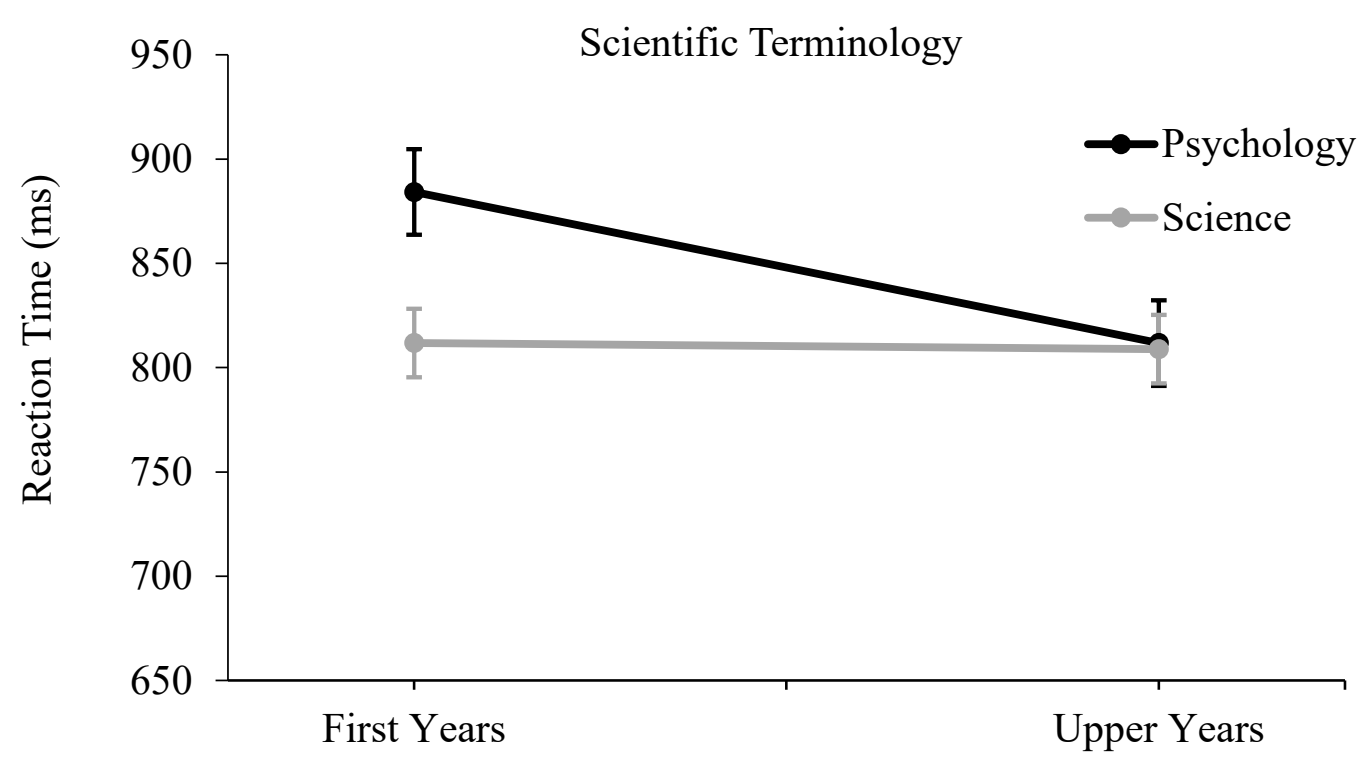

Figure 4. Scientific Terminology. Error bars represent the standard error.

First year students were significantly quicker to respond to "science" when it was paired with these terms compared to "psychology" $(M D=72.44, p=.001)$. Thus, for first years, "difficult", "important", and "fact" appear to be more representative of science than psychology at an implicit level. In contrast, upper year students associated "psychology" or "science" with these terms to the same degree. Overall, these results suggest that even at an implicit level, with a psychology-specific education, psychology comes to be increasingly more associated with terminology that is considered to be more denotive of science.

Conceptions of Psychology. Next, it was of interest to determine whether "psychology" and "science" were differentially associated with terminology more typically denotative of psychology. Thus, for each participant an average RT was calculated for "psychology" when paired with "easy", "subjective", and "useless" and for "science" when paired with these three terms. To explore potential differences and between groups, a 2 (group: first years vs. upper years) x 2 (psychological terms with: psychology vs. science) Mixed-Design ANOVA was 
conducted. These results are presented in Figure 5. Surprisingly, this analysis revealed a significant main effect of pair, $F(1,101)=8.29, p=.005$, partial $\eta^{2}=.08$, indicating that participants as a whole were quicker to respond to these terms when paired with "science" $(M=$ $812.25, S E=16.03)$ rather than "psychology" $(M=856.39, S E=17.25)$. The main effect of group was non-significant, however, $F(1,101)=1.35, p=.248$, partial $\eta^{2}=.01$. Finally, the interaction between word-pair and year of study was significant, $F(1,101)=12.98, p<.001$, partial $\eta^{2}=.11$. However, the interaction was no longer significant when correcting the RTs for word frequency, $F(1,102)=3.85, p=.052$, partial $\eta^{2}=.036$.

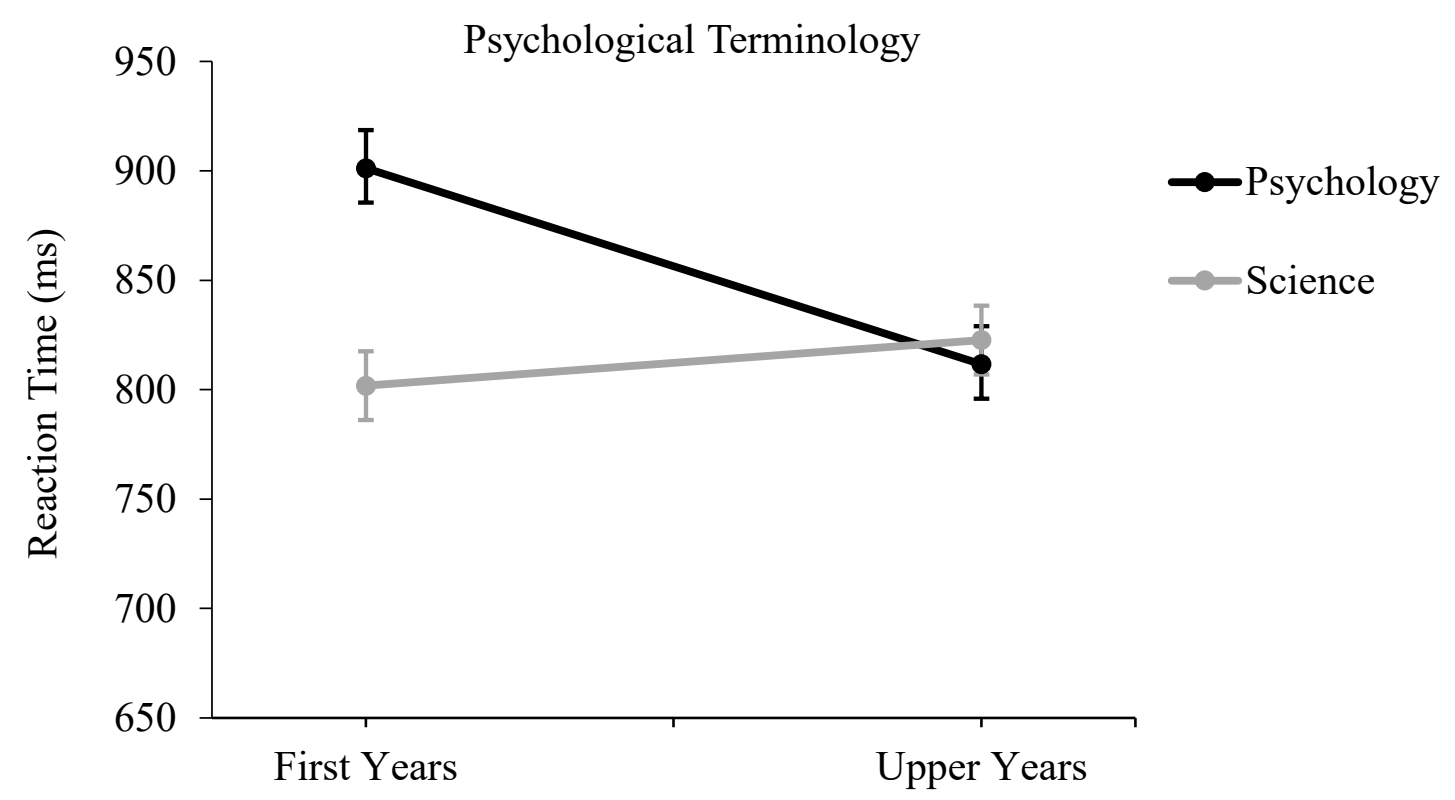

Figure 5. Psychological Terminology. Error bars represent the standard error.

As illustrated, first year students were significantly slower to respond to these terms when they were paired with "psychology" compared to "science" $(M D=99.35, p<.001)$. Upper year students, however, did not differentially associate psychology or science with these terms. The simple main effects between groups demonstrated that upper year students were significantly quicker to respond to "psychology" and this terminology compared to first year 
students $(M D=89.60, p=.011)$. However, this simple main effect was no longer significant when correcting the RTs for word frequency $(M D=.045, S E=.03, p=.14)$.

Science and subject matter. To assess whether certain topics of study were more implicitly associated with science and whether this depended on year of study, a 2 (group: first year vs. upper year) x 6 (science with brain, mind, behavior, animal, chemical, gravity) MixedDesign ANOVA was conducted. These RTs are presented in Figure 6. The results revealed a non-significant interaction between year of study and topic, $F(5,440)=.951, p=.45$, partial $\eta^{2}=$ .01. The main effect of topic, however, was significant, $F(5,440)=6.27, p<.001$, partial $\eta^{2}=$ .066. As a whole, participants were the quickest to respond to "science" when it was paired with "brain" $(M=696.29, S E=19.37)$, followed by "mind" $(M=731.92, S E=21.01)$, "animal" $(M=$ $777.34, S E=22.58)$, "chemical" $(M=784.93, S E=22.07)$, "behavior" $(M=786.45, S E=$ $25.15)$, and "gravity" $(M=821.25, S E=22.36)$. Furthermore, there was a significant main effect of year of study whereby first years students were slower to respond to these pairs compared to upper year students, $F(1,88)=4.34, p=.04$, partial $\eta^{2}=.05$.

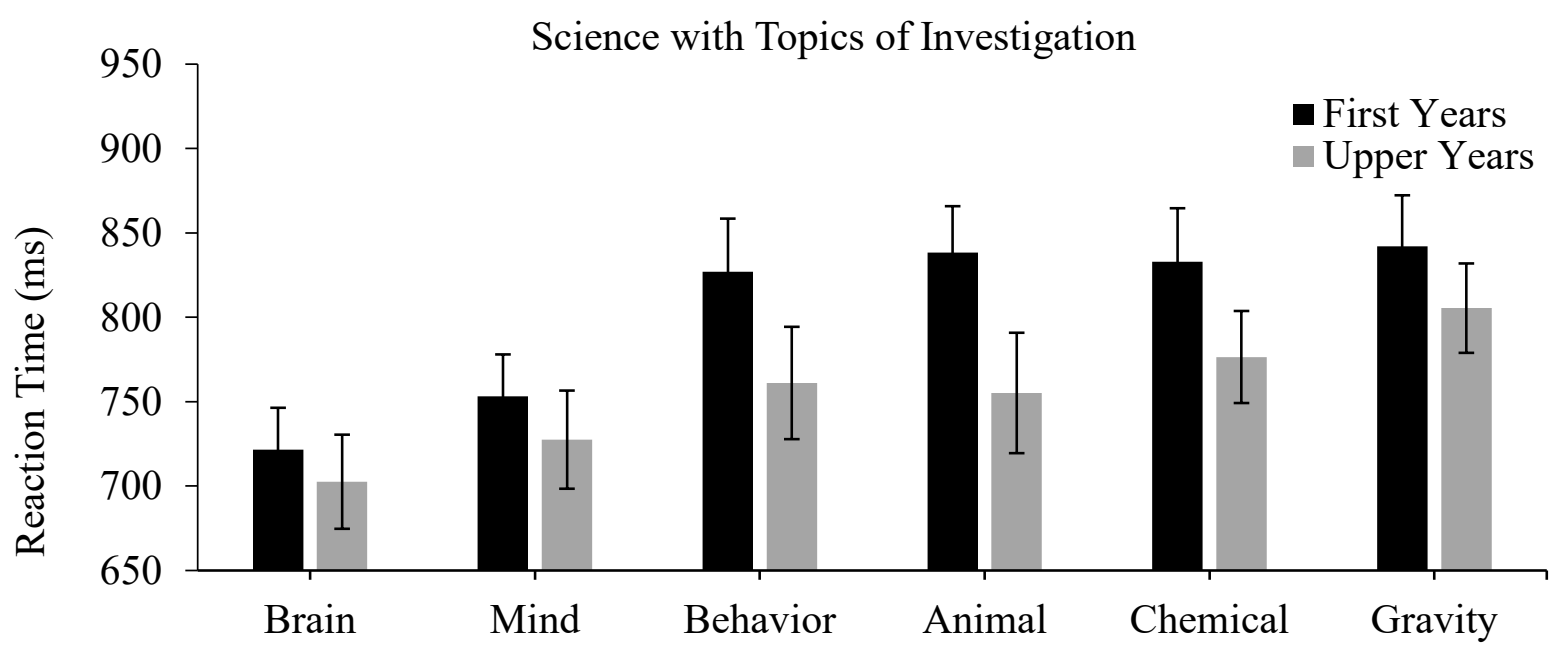

Figure 6. Science with Topics of Investigation. Error bars represent the standard error. 
Psychology with its topics of investigation. Previous research has determined that psychology is associatively related to the brain, mind, and behavior (Morgan, 2015, 2018). The next set of analyses aimed to determine whether these topics of study are associated with psychology at an implicit level, and whether such associations are similar between first and upper year students. Thus, a 2 (group: first year vs. upper year) x 3 (psychology with brain, mind, and behavior) Mixed-Design ANOVA was conducted. The RTs are presented in Figure 7. A significant main effect of pair was found whereby participants were slowest to respond to "psychology" when presented with "behavior" $(M=859.74, S E=26.40)$, relative to "brain" ( $M$ $=784.98, S E=22.85)$, or "mind" $(M=735.62, S E=17.12), F(2,178)=10.93, p<.001$, partial $\eta^{2}=.11$ ). The main effect of for year of study, however, demonstrated no significant differences between first year $(M=805.25, S E=21.35)$ and upper year students' RTs $(M=781.64, S E=$ 24.65), $F(1,89)=.52, p=.47$, partial $\eta^{2}=.006$. The interaction between both year of study and psychology topics was non-significant, $F(2,178)=.75, p=.47$, partial $\eta^{2}=.008$.

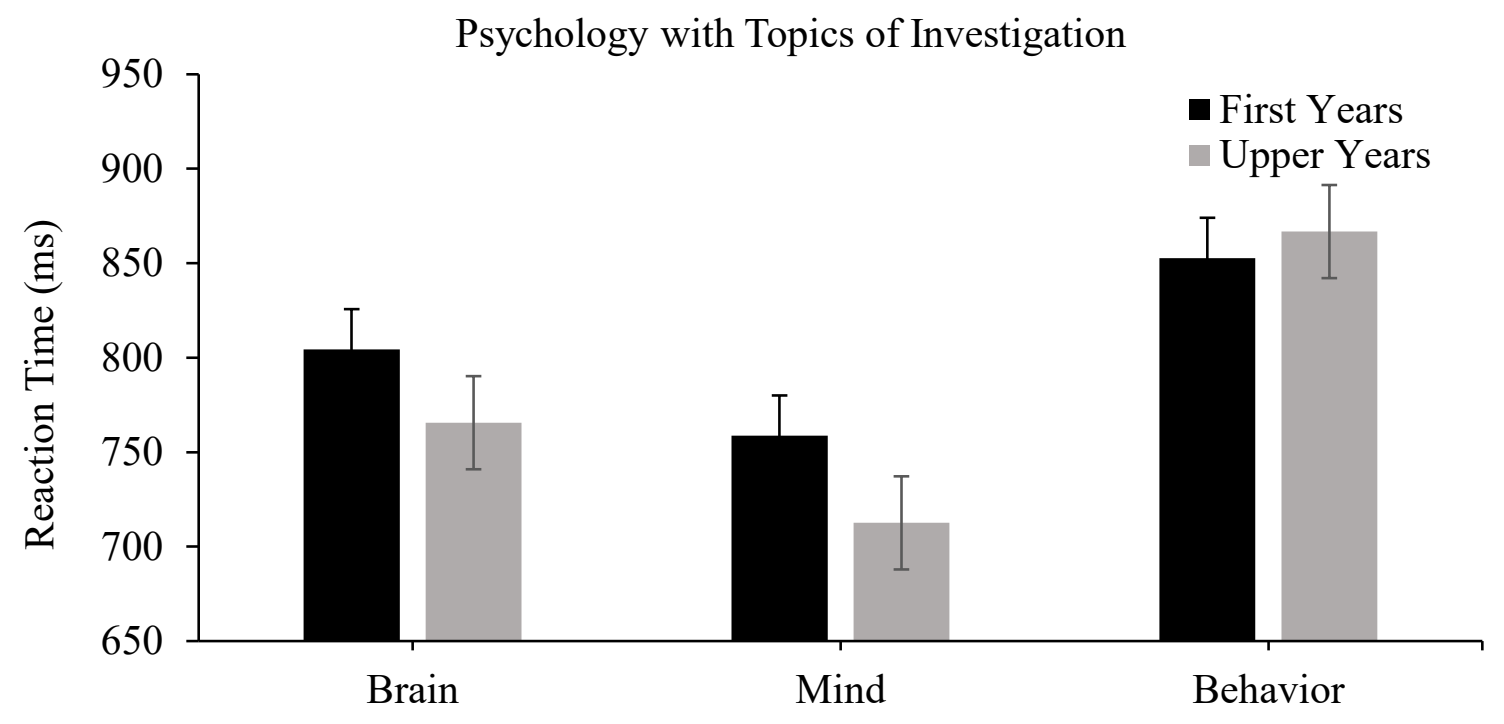

Figure 7. Psychology with its Topics of Investigation. Bars represent the standard error. 


\section{Explicit Responses}

The next set of analyses examined the participants' answers to direct question about the nature of psychology as a discipline. Responses to the question "Do you believe that psychology is a science?" were analyzed first. Of the first year students, $91.3 \%$ believed that psychology is a science, compared to $93.5 \%$ of upper year students. Moreover, $97.1 \%$ of first year students and 95.7\% of upper year students agreed that "psychology employs the scientific method". Thus, only two participants in each group indicated no. Compared to all other methods used in this experiment, these questions arguably represented the most explicit and direct ways in which participants were assessed on their endorsement of psychology as a science. Evidently, this method also demonstrated that overall, an overwhelming majority of participants did in fact believe that psychology was both a science and adhered to the scientific method.

To determine whether students would similarly endorse psychology as a science on an explicit measure that was somewhat less direct, responses to "Are you majoring in a scientific discipline?" were assessed only for those who were in fact majoring in psychology. As noted, only nine introduction to psychology students were psychology majors. Of these participants, however, only four stated that they were majoring in a scientific discipline. Of the upper year students, 36 were majoring in psychology and only 14 (or 39\%) stated that they were majoring in a scientific discipline. Compared to the responses generated when participants were directly asked whether psychology was a science, this less direct measure clearly demonstrated less scientific attitudes towards psychology. Thus, the beliefs of psychology as a science seem to somewhat differ depending on the method used to assess this belief.

Psychology as a science scale. Participant scores for each factor on the PAS were summed individually to examine differences along each component of the scale. An overall 
aggregate score that included all 15 items was also calculated. Note that each factor contained 5, 4, and 6 items respectively, and each item was responded to on a 7-point Likert scale. Thus, the maximum score participants could have received was 105. First and upper year students' PAS scores are presented in Table 3. According to an independent sample $t$-test, upper year psychology students scored significantly higher on the PAS compared to first year students, $t(111)=-2.34, p=.021$. Thus, according to this explicit measure, those with greater exposure to psychology indicated that it is a science more than those recently exposed to the field.

Table 3

PAS and SPI Scores for first and upper year students.

\begin{tabular}{lllllll}
\hline & First Years & $S D$ & Upper Years & $S D$ & Total & $S D$ \\
\hline Scientific interests & 24.59 & 6.58 & 27.31 & 9.03 & 25.67 & 7.72 \\
Practitioner interests & 28.23 & 6.19 & 32.71 & 5.94 & 30.00 & 6.45 \\
PAS - Factor 1 & 20.81 & 3.65 & 22.11 & 3.13 & 21.33 & 3.49 \\
PAS - Factor 2 & 26.07 & 4.37 & 27.82 & 4.85 & 26.77 & 4.62 \\
PAS - Factor 3 & 29.97 & 4.46 & 31.51 & 5.36 & 30.58 & 4.87 \\
Total PAS Scores & 76.85 & 9.89 & 81.44 & 10.70 & 78.68 & 10.42 \\
\hline
\end{tabular}

To further explore which particular elements of the PAS scale contained the greatest mean difference between year of study, three additional $t$-tests were performed. For factor one, which assesses the degree to which people believe that psychology should be placed in the same conceptual category as the hard sciences, upper year psychology students scored higher than first year students, but this difference was only marginally significant, $t(111)=-1.96, p=.052$. For factor two, which assesses the degree to which people believe psychology employs the scientific method, upper year psychology students scored significantly higher than first year students, $t(111)=-1.99, p=.049$. Finally, for factor three which assesses the degree that people believe that psychological phenomena can truly be understood by means of a scientific process, upper 
year psychology students did not score significantly higher than first year students, $t(111)=$ $1.66, p=.1$.

Scientist-Practitioner Inventory. A sum was calculated for each participant on the nine practitioner and nine scientist items of the SPI. Participants responded to the SPI using a 5-point Likert scale. Thus, the maximum score they could have obtained for either scientific or practitioner interests was 45 . These scores for first and upper year students are presented in Table 3. For the sample as a whole, a paired samples $t$-test demonstrated that participants possessed significantly greater practitioner interest compared to scientific ones, $t(113)=7.18, p$ $<.001$. Moreover, contrary to what was hypothesized, an independent sample $t$-tests demonstrated significantly greater practitioner interests among upper year psychology students compared to first year students, $t(112)=-3.84, p<.001$. There were no significant differences, however, in upper year and first year students' scientific interests, $t(112)=-1.74, p=.086$.

\section{The correlations among the implicit and explicit measures}

The final set of analyses was aimed at assessing the correlations among all measures used in the experiment. Table 4 presents the correlations between the RTs for "psychology-science", “psychology-methodological terminology”, "psychology-difficult, important, fact”, practitioner and scientific interests, as well as PAS scores for first year students. Table 5 presents these correlations for upper year students. 
Table 4

Correlations amongst measures for first year students.

\begin{tabular}{|c|c|c|c|c|c|c|c|c|c|}
\hline & 1 & 2 & 3 & 4 & 5 & 6 & 7 & 8 & 9 \\
\hline 1.“Psychology-Science” RTs & 1 & $.53 * *$ & $.66^{* *}$ & .08 & .11 & .02 & .09 & -.08 & -.11 \\
\hline 2. "Psychology-Methods" RTs & & 1 & $.67 * *$ & $.25^{*}$ & .22 & .19 & $.28 *$ & .22 & .20 \\
\hline 3. "Psychology-Science Terms" & & & 1 & .18 & .25 & .14 & .24 & .18 & -.07 \\
\hline 4. PAS - Factor 1 & & & & 1 & $.28 *$ & $.41 * *$ & $.68 * *$ & $.25 *$ & $.41 * *$ \\
\hline 5. PAS - Factor 2 & & & & & 1 & $.63 * *$ & $.82 * *$ & $.29 *$ & $.30 *$ \\
\hline 6. PAS - Factor 3 & & & & & & 1 & $.87 * *$ & .21 & $.27 *$ \\
\hline 7. Overall PAS Scores & & & & & & & 1 & $.31 *$ & $.41 * *$ \\
\hline 8. Scientific interests & & & & & & & & 1 & $.57 * *$ \\
\hline 9. Practitioner interests & & & & & & & & & \\
\hline
\end{tabular}

Note. $* p<.05, * * p<.01$

Table 5

Correlation amongst measures for upper year students.

\begin{tabular}{|c|c|c|c|c|c|c|c|c|c|}
\hline & 1 & 2 & 3 & 4 & 5 & 6 & 7 & 8 & 9 \\
\hline 1. "Psychology-Science" RTs & 1 & $.59 * *$ & $.50 * *$ & -.10 & -.17 & .04 & -.11 & -.16 & .01 \\
\hline 2. "Psychology-Methods" RTs & & 1 & $.64 * *$ & .04 & -.09 & -.14 & -.11 & -.09 & .03 \\
\hline 3. "Psychology-Science Terms" & & & 1 & -.10 & -.08 & -.14 & -.16 & -.08 & -.03 \\
\hline 4. PAS - Factor 1 & & & & 1 & -.03 & .09 & $.45 * *$ & .08 & .05 \\
\hline 5. PAS - Factor 2 & & & & & 1 & $.39 * *$ & $.72 * *$ & $.36^{*}$ & .02 \\
\hline 6. PAS - Factor 3 & & & & & & 1 & $.79 * *$ & .14 & .19 \\
\hline 7. Overall PAS Scores & & & & & & & 1 & .29 & .14 \\
\hline 8. Scientific interests & & & & & & & & 1 & $.60 * *$ \\
\hline 9. Practitioner interests & & & & & & & & & \\
\hline
\end{tabular}

Note. ${ }^{*} p<.05,{ }^{* *} p<.01$

Correspondence between PAS and SPI. First year students' PAS scores were

significantly correlated with greater scientific interests and all three factors on the PAS were significantly correlated among each other. Furthermore, PAS scores were also significantly correlated with greater practitioner interests, albeit to a slightly lesser extent. Thus, greater interest in psychology more generally - regardless of which domain was of greater interest appeared to foster greater beliefs in psychology as a science. For upper year students, however, PAS scores were not correlated with either scientific nor practitioner interests. Furthermore, 
only factor 2 and 3 were significantly correlated. Thus, for these students, a greater belief that psychological phenomena are compatible with the scientific methodology was positively related to beliefs that psychology used a scientific method.

Correlations among implicit and explicit measures. To determine whether implicit and explicit measures in this study were associated, the correlations among the RTs for "psychologyscience" and scores on the PAS were examined. Both measures were not significantly correlated in the full sample, $r(98)=-.029, p=.78$. Thus, participants' explicit and implicit responses do not appear to be related. Furthermore, as shown in Tables 3 and 4, the RTs for "psychologyscience" were not significantly correlated with any factor on the PAS, nor scientific or practitioner interests. The same was true for "psychology-methods" RTs and "psychologyscientific terminology" RTs except that first year students "psychology-methods" RTs were significantly correlated with factor 1 on the PAS.

\section{Discussion}

People are generally skeptical of psychology's status as a science (Benjamin et al., 1986; Lilienfeld, 2010; Ferguson, 2015). Even those within the psychological community have demonstrated a bias to conceive the hard sciences as being scientifically superior to psychology (Biglan, 1984; Ryan, 2015; Webb \& Speer, 1986). The present study was motivated by the need to examine scientific attitudes about psychology while ensuring that students are not merely responding in a socially desirable way. Thus, the goal of the current experiment was to assess psychology students' implicit attitudes towards the discipline. To achieve this goal, a go/no-go LDT was administered to introduction to psychology students and upper year psychology students (Perea et al., 2002). The participants were asked to respond to word-word pairs involving scientific and psychological terminology. The relative ease with which participants were able to make lexical decisions were taken as a measure of implicit association (Fazio \& 
Olsen, 2003). The primary associations of interests were those between "psychology" and science, words denotive of people's concept of science, topics investigated in the sciences, as well as methodological terminology. Following the completion of this implicit measure, participants also completed the PAS and SPI to assess their explicitly held beliefs towards psychology as a science. Finally, to more directly assess this belief, participants were forthright asked "Is psychology a science?"

\section{Psychology and science}

The most important finding that emerged from this study was that students with greater exposure to the psychological curriculum develop stronger implicit associations between "science" and "psychology" compared to students just being introduced to the discipline. Impressively, upper year students were more than 100 milliseconds quicker to respond to "psychology-science" compared to introduction to psychology students. Previous research has documented the benefits of completing advanced psychology coursework (Amsel et al., 2011) such as research methods (Friedrich, 1996), statistics, and Honours theses (Pettijohn et al., 2015) on the belief that psychology is a science according to the PAS. Consistent with this research, our sample which included students that were taking these more advanced psychology courses similarly displayed a significant increase in PAS scores. Our results lend greater credence to the fact that changes on explicit measures are not merely a product of students responding in socially desirable ways as other research might have implied (Bartels, Hinds, Glass, \& Ryan, 2009). Rather, students appear to undergo a more robust change in their scientific attitudes towards psychology that occur at a more basic level of processing.

Our results similarly demonstrated a decrease in upper year students' response times for the "neuroscience-science" pair. This is likely because neuroscience is a highly infrequent word 
- especially compared to the other science disciplines used in our experiment. In fact, of all the 22 stimuli presented to participants, "neuroscience" displayed the lowest word frequency (Brysbaert \& New, 2009). Neuroscience is not generally taught at the high school level, potentially explaining why it was the slowest among the "science-discipline" pairs for first year students. Rather, neuroscience is typically a discipline that is taught at a university level, giving upper year students greater exposure to the subject. Although first and upper year students did not significantly differ in the speed at which they responded to this pair, it was the only other “science-discipline" pair which displayed a decrease in RTs.

\section{Psychology and the scientific method}

Science is defined by its use of an empirical approach to understand phenomena. The majority of our participants, irrespective of year of study, agreed that psychology employs the scientific method when asked directly. This belief was also examined using Fridrich's (1996) PAS scale. The scale contains a factor that exclusively measures people's belief that experimentation plays a fundamental role in psychology. Research that has administered the PAS scale has overlooked the value in presenting students' change in beliefs on this factor alone. Our results showed that upper year students scored significantly higher than first year students. In fact, it was the only PAS factor that displayed significantly higher scores score for upper year students. Thus, despite negligible differences between first and upper year students' responses to the question "Does psychology employ a scientific method?", significant differences between groups were observed along an explicit measure that was somewhat less direct. Ideally, gaining knowledge about psychology's use of the scientific method should bolster beliefs that it is a science. The present results found that those that more strongly supported experimentation 
within psychology were also more likely to agree that psychology should be granted the same scientific status as the hard sciences.

In addition, the LDT results provided evidence that the changes observed in PAS scores may also occur at an implicit level. It was hypothesized that upper year students would be quicker at responding to methodological terminology when presented with psychology compared to first year students. This hypothesis was supported. Thus, efforts to teach students that psychology follows the same guiding principles of science appear to have an impact at an implicit level. Moreover, upper year students appeared to implicitly associate both psychology and science with methodological terminology to the same extent. This is in contrast with research that has explored the semantic network of science, which found that reference to methodology are more common for science as a whole than the scientific disciplines (Morgan, 2015, 2018; Hernandez, 2016). Furthermore, the data revealed that greater implicit association between "psychology" and methodological terminology predicted greater PAS scores for first year students. This was not true of upper year students, however. Thus, as hypothesized, there appears to be a greater correspondence between implicit and explicit measures for first year students compared to upper year students.

\section{Science and its topics of study}

Previous research has identified the brain as a prototypical image of science (Baker et al., 2015, p. 253; Feigenson, 2006). Correspondingly, the present sample as a whole was quickest to respond to science when presented with the "brain". An unanticipated result, however, demonstrated that for both first and upper year students, science was second most associated with the "mind". Notably, mind represented the word with the highest frequency count within the experiment. However, even after considering the RTs adjusted for word frequency, the mind 
remained the most implicitly associated with science. Some research has found evidence to suggest that dualist theories - or beliefs that one must discriminate between the functioning of the brain and the mind—could potentially explain psychology's unscientific image (Morgan, 2018). Specifically, while the brain is viewed as a concrete, tangible, and knowable entity, the mind - perceived as more abstract—does not seem compatible with a scientific line of inquiry. Our results show that at an implicit level, the mind is in fact regarded as a strong associate of science, however. Furthermore, some lines of research have postulated that psychology's unscientific status stems from the discipline's investigation of phenomena that do not resemble the topics of hard sciences (Hopkins, Weisberg, \& Taylor, 2016; Krull \& Silvera, 2013). Our results, however, demonstrated that the brain was strongly associated with psychology, even more so than behavior.

Notably, researchers have speculated that the underpinnings of psychology's unscientific image may stem from the topic of study, rather than methodology, defining people's perception of science. Our findings that participants overall were some 70 milliseconds quicker at responding to "science" when presented with topics of study (i.e., brain, gravity, animal, behavior, mind, chemical) compared to methodological terminology (i.e., analysis, experiment, observation, hypothesis) may further support these conclusions.

\section{The concept of science versus the concept of psychology}

Research has identified "difficult", "important", and "fact" as the most characteristic features of science. Furthermore, these attributes, while strong associates of science, are not representative of psychology (Estes et al., 2003; Hernandez, 2015; Hofer, 2000; Janda et al., 1998). Thus, the present study postulated that psychology not being credited with these features could potentially explain its unscientific image. The methods that have been employed to assess 
and document the disparities in how psychology and science are accredited with these features have primarily employed explicit measures. The present data showed that this disparity persists at an implicit level as well, at least for first year students. For upper year students, however, no distinction was found in associations when "psychology" and "science" were paired with these terms.

This is peculiar, however, given that even those with knowledge and experience in psychology judge it to be a less important discipline (Janda et al., 1998). This upper year sample, however, showed that at an implicit level psychology was perceived as important. Psychology also became increasingly associated with "fact". It is unclear how to view these findings, however. On the one hand, science is not a method that produces facts, but theories. Facts, however, are often seen as a defining characteristic of science (Estes et al., 2003; Hofer, 2000). Psychology's increased association with "fact", therefore, could be a sign of the discipline's improving scientific image among upper year students, but may also display a perpetuation of an overall misrepresentation of science as a whole.

What was surprising, however, was that psychology's implicit associations with "easy", "subjective", and "useless" were also strengthened for upper year students. It seems odd that psychology could be associated with both "important" and "useless" or "easy" and "hard". To explain these apparent contradictory beliefs, it is reasonable to speculate that upper year students' experience with psychology enabled them to retrieve examples where psychology was "easy" or "hard" and "important" or "useless".

Research on counterstereotypic exemplars supports this possibility. For instance, Gonsalkorale et al. (2010) primed White participants with positive-Black and negative-White exemplars and subsequently asked them to complete an Implicit Attitude Test. Their results 
demonstrated that these counterstereotypic exemplars reduced participants' implicit racial biases. Within the context of this experiment, it is possible that upper year psychology students are repeatedly exposed to counterstereotypic exemplars that challenge the typical attitudes towards psychology. For instance, while psychology has been found to be judged as an easier discipline compared to the hard sciences, students' experiences in research methods, statistics, and advanced content courses may increase their implicit "psychology-difficult" associations. This increase does not lead to a decrease in implicit "psychology-easy" associations, however. That is, exposure to counterstereotypic exemplars does not necessarily serve to eliminate old attitudes (Scherer \& Lambert, 2009).

\section{Limitations and future direction}

The results of this study provide some evidence that educators' efforts to present psychology as a science may impact students' understanding of their discipline at implicit level. While goal of this experiment was to examine participants' implicit beliefs, the adopted go/no-go LDT presented some challenges. Specifically, the stimuli used in the experiment exhibited a range of lexical properties, which have demonstrated to affect response times (Perea et al., 2002). Researchers that implement this measure typically control for word frequency effects a priori to ensure that response times measure strength of association rather than word processing speed. The present study, however, examined the impact of word frequency on the participants' response times. It was found that even when they had been controlled for, the effect was largely the same. Students with greater exposure to the psychological curriculum more implicitly associated psychology with science.

Nonetheless, researchers that wish to explore similar questions would be advised to implement measures to mitigate this challenge. Specifically, participants could be asked to 
respond to the experimental words presented in isolation. This would yield baseline response times for each word individually, which could then be used to control for overall processing fluency effects. Moreover, while the go/no-go LDT offers several advantages over the traditional LDT, such as smaller error rates and quicker RTs, the traditional "yes/no" task may be more beneficial in instances where word frequencies cannot be controlled for a priori. Additionally, it is recommended that future research include stimuli that represent a greater variety of disciplines. The current experiment only used scientific terminology or associates of science. By including humanities disciplines in this task, psychology's implicit associations with science as compared with other types of fields could be examined. For instance, although the results from this study demonstrated that upper year students more increasingly associated psychology with science, it is also possible that at the same time they increasingly associate philosophy and other non-scientific disciplines with psychology.

Finally, it is important to address some limitations with respect to the sample of participants. Specifically, the majority of introduction to psychology students were not majoring in psychology. One might expect psychology majors to differ in opinion from those taking courses as electives. Introduction to psychology students, however, might arguably hold similar attitudes towards psychology as non-psychology students. That is because both introduction to psychology students and non-psychology majors both similarly have not received the psychology-specific education. Nonetheless, exploring psychology majors' attitudes exclusively would prove beneficial.

\section{Conclusion}

Psychology is regarded as scientifically inferior to the hard sciences even though it adheres to the same guiding principles of science. Students' scientific attitudes towards 
psychology are well documented within the literature. Specifically, research has shown that students that have more opportunities to learn about the discipline - such as those further along in the curriculum and those that have complete more advanced psychology courses - are more inclined to believe that psychology is a science. Such research has more narrowly adopted explicit measures, however, making it unclear whether such changes can occur at an implicit level as well. To address this issue, the current experiment adopted an implicit measure by means of a go/no-go LDT. Our results demonstrated that students do come to associate psychology with science after acquiring greater psychology-specific education. Hence, future research about people's conception of psychology as a science may want to adopt both explicit and implicit measure to obtain a more comprehensive picture. 


\section{References}

Acosta, S., \& Hsu, H. (2014). Shared academic values: Testing a model of the association between hong kong parents' and adolescents' perception of the general value of science and scientific literacy. Educational Studies, 40(2), 174-195. doi:http://dx.doi.org.proxy.library.carleton.ca/10.1080/03055698.2013.866889

Amsel, E., Baird, T., \& Ashley, A. (2011). Misconceptions and conceptual change in undergraduate students' understanding of psychology as a science. Psychology Learning \& Teaching, 10(1), 3-10. doi:http://dx.doi.org.proxy.library.carleton.ca/10.2304/plat.2011.10.1.3

Amsel, E., Johnston, A., Alvarado, E., Kettering, J., Rankin, L., \& Ward, M. (2009). The effect of perspective on misconception in psychology: A test of conceptual change theory. Journal of Instructional Psychology, 36(4), 289-295. Retrieved from http://proxy.library.carleton.ca/login?url=https://search-proquestcom.proxy.library.carleton.ca/docview/742995172?accountid=9894

Baker, D. A., Ware, J. M., Schweitzer, N. J., \& Risko, E. F. (2015). Making sense of research on the neuroimage bias. Public Understanding of Science. http://doi.org/10.1177/0963662515604975

Balota, D. A., \& Chumbley, J. I. (1984). Are lexical decisions a good measure of lexical access? the role of word frequency in the neglected decision stage. Journal of Experimental Psychology: Human Perception and Performance, 10(3), 340-357. doi:http://dx.doi.org.proxy.library.carleton.ca/10.1037/0096-1523.10.3.340

Balota, D.A., Yap, M.J., Cortese, M.J., Hutchison, K.A., Kessler, B., Loftis, B., Neely, J.H., Nelson, D.L., Simpson, G.B., \& Treiman, R. (2007). The English Lexicon Project. Behavior Research Methods, 39, 445-459. 
Banaji, M. R., Lemm, K. M., \& Carpenter, S. J. (2001). Automatic and implicit processes in social cognition. In A. Tesser \& N. Schwartz (Eds.), Blackwell Handbook of Social Psychology: Intraindividual Processes (pp. 134-158). Oxford: Blackwell.

Bartels, J. M., Hinds, R. M., Glass, L. A., \& Ryan, J. J. (2009). Perceptions of psychology as a science among university students: The influence of psychology courses and major of study. Psychological Reports, 105(2), 383-388.

doi:http://dx.doi.org.proxy.library.carleton.ca/10.2466/pr0.105.2.383-388

Barrow, R. (2000). Determining stereotypical images of psychologists: The draw A psychologist checklist. College Student Journal, 34(1), 123-132. Retrieved from http://proxy.library.carleton.ca/login?url=https://search-proquestcom.proxy.library.carleton.ca/docview/619456891 accountid $=9894$

Benjamin, L. T. Jr. (1986). Why don’t they understand us? A history of psychology’s public image. American Psychologist, 32: 205-210.

Berezow, A. B. (2012, July 13). Why psychology isn't science. Los Angeles Times. Retrieved from http://articles.latimes.com/2012/jul/13/news/la-ol-blowback-psychologyscience 20120713.

Besche-Richard, C., Passerieux, C., \& Hardy-Baylé, M. (2005). Double-decision lexical tasks in thought-disordered schizophrenic patients: A path towards cognitive remediation? Brain and Language, 95(3), 395-401. doi:http://dx.doi.org.proxy.library.carleton.ca/10.1016/j.bandl.2005.03.003

Biglan, A. (1973). The characteristics of subject matter in different academic areas.Journal of Applied Psychology, 57(3), 195-203. doi:http://dx.doi.org.proxy.library.carleton.ca/10.1037/h0034701 
Blair, I. V., Ma, J. E., \& Lenton, A. P. (2001). Imagining stereotypes away: The moderation of implicit stereotypes through mental imagery. Journal of Personality and Social Psychology, 81, 828-841.

Braxton, J. M., and Hargens, L. L. (1996). Variation in academic disciplines: Analytical frameworks and research. In J. S. Smart (ed), Higher Education: Handbook of Theory and Research, vol XI. (pp. 1士46). New York: Agathon Press.

Brinthaupt, T. M., Hurst, J. R., \& Johnson, Q. R. (2016). Psychology degree beliefs and stereotypes: Differences in the perceptions of majors and non-majors. Psychology Learning \& Teaching, 15(1), 77-93. doi:http://dx.doi.org.proxy.library.carleton.ca/10.1177/1475725716642116

Brooks, D. (2010, June 28). Bill Wilson's gospel. The New York Times. Retrieved from http://www.nytimes.com/2010/06/29/opinion/29brooks .html

Brysbaert, M. \& New, B. (2009) Moving beyond Kucera and Francis: A Critical Evaluation of Current Word Frequency Norms and the Introduction of a New and Improved Word Frequency Measure for American English. Behavior Research Methods, 41 (4), 977-990. Cacioppo, J. T., \& Berntson, G. G. (1992). Social psychological contributions to the decade of the brain: Doctrine of multilevel analysis. American Psychologist, 47(8), 1019-1028. doi:http://dx.doi.org.proxy.library.carleton.ca/10.1037/0003-066X.47.8.1019

Carli, L. L., Alawa, L., Lee, Y., Zhao, B., \& Kim, E. (2016). Stereotypes about gender and science: Women $\neq$ scientists. Psychology of Women Quarterly, 40(2), 244-260. doi:http://dx.doi.org.proxy.library.carleton.ca/10.1177/0361684315622645

Caswell, M. (2014). Psychology Is Not a Science. Retrieved February 01, 2016, from https://www.scienceleadership.org/blog/Psychology_Is_Not_a_Science 
Chaiken S, Trope Y, eds. 1999. Dual Process Theories in Social Psychology. New York: Guildford

Chalmers, A. F. (2013). What Is This Thing Called Science? 4th edn. University of Queensland Press, St Lucia.

Chambers, D.W. (1983) Stereotypic images of scientists: the draw-a-scientist test, Science Education, 67, pp. 255-265.

Cheng, Y., Payne, J. and Witherspoon, S. (1995). Science and mathematics in full-time education after 16: England and Wales Youth Cohort Study (London: Department for Education and Employment).

Cole, S. (1983). The Hierarchy of the Sciences?. American Journal of Sociology, 89(1), 111139. Retrieved from http://www.jstor.org/stable/2779049

Collins, A. M., \& Quillian, M. R. Facilitating retrieval from semantic memory: The effect of repeating part of an inference. Acta Psychologica, 1970, 33, 304-314.

Collisson, B., Kellogg, J., \& Rusbasan, D. (2015). Perceptions of psychology as a science: The effect of citations within introductory textbooks. North American Journal of Psychology, 17(1), 77-88. Retrieved from http://search.proquest.com.proxy.library.carleton.ca/docview/1683363899?accountid=98 94

Comte, A. (1853) The positive philosophy. London: Bell.

Conant, James B. 1950. Forward to Harvard Case Studies in Experimental Science. Cam- bridge, Mass.: Harvard University Press.

Conrey, 2005 Separating Multiple Processes in Implicit Social Cognition: The Quad Model of Implicit Task Performance 
Cvencek, D., Meltzoff, A. N., \& Greenwald, A. G. (2011). Math-gender stereotypes in elementary school children. Child Development, 82(3), 766-779. doi:http://dx.doi.org.proxy.library.carleton.ca/10.1111/j.1467-8624.2010.01529.x

Dannenbring, G. L., \& Briand, K. (1982). Semantic priming and the word repetition effect in a lexical decision task. Canadian Journal of Psychology/Revue Canadienne De Psychologie, 36(3), 435-444. doi:http://dx.doi.org.proxy.library.carleton.ca/10.1037/h0080650

Dasgupta, N., \& Greenwald, A. G. (2001). On the malleability of automatic attitudes: Combating automatic prejudice with images of admired and disliked individuals. Journal of Personality and Social Psychology, 81, 800-814

Del Favero, M. (2006). An examination of the relationship between academic discipline and cognitive complexity in academic deans' administrative behavior.Research in Higher Education, 47(3), 281-315. Retrieved from http://proxy.library.carleton.ca/login?url=https://search-proquestcom.proxy.library.carleton.ca/docview/62099451 accountid=9894

Dempsey, S. (2007). The public perception of clinical psychologists: A discursive analysis. Australian Psychologist, 42(1), 2-14. doi:http://dx.doi.org.proxy.library.carleton.ca/10.1080/00050060600726320

Driver, R., Newton, P., \& Osborne, J. (2000). Establishing the norms of scientific argumentation in classrooms. Science Education, 84, 287-312.

Estes, D., Chandler, M., Horvath, K. J., \& Backus, D. W. (2003). American and british college students' epistemological beliefs about research on psychological and biological 
development. Journal of Applied Developmental Psychology, 23(6), 625-642.

doi:http://dx.doi.org.proxy.library.carleton.ca/10.1016/S0193-3973(03)00002-9

Evans, J. S. B. T. (2008). Dual-processing accounts of reasoning, judgment, and social cognition. Annual Review of Psychology, 59, 255-278.

doi:http://dx.doi.org.proxy.library.carleton.ca/10.1146/annurev.psych.59.103006.09

Farah, M. J., \& Hook, C. J. (2013). The seductive allure of "seductive allure".Perspectives on Psychological Science, 8(1), 88-90.

doi:http://dx.doi.org.proxy.library.carleton.ca/10.1177/1745691612469035.

Fazio, R. H., \& Olson, M. A. (2003). Implicit measures in social cognition research: Their meaning and uses. Annual Review of Psychology, 54, 297-327. doi:http://dx.doi.org.proxy.library.carleton.ca/10.1146/annurev.psych.54.101601.

Fazio, R. H., Jackson, J. R., Dunton, B. C., \& Williams, C. J. (1995). Variability in automatic activation as an unobtrusive measure of racial attitudes: A bona fide pipeline? Journal of Personality and Social Psychology, 69, 1013-1027.

Fazio, Russell H. 1990. "Multiple Processes by Which Attitudes Guide Behavior: The MODE Model as an Integrative Framework." In Advances in Experimental Social Psychology. Volume 23. Ed. Mark P. Zanna. New York: Academic Press, 75-109

Feigenson, N. (2006). Brain imaging and courtroom evidence: On the admissibility and persuasiveness of fMRI. International Journal of Law in Context, 2(3), 233-255. doi:10.1017/S174455230600303X

Ferguson, C. J. (2015). "Everybody knows psychology is not a real science": Public perceptions of psychology and how we can improve our relationship with policymakers, the scientific community, and the general public. American Psychologist, 70(6), 527-542. 
Fernandez-Duque, D., Evans, J., Christian, C., \& Hodges, S. D. (2015). Superfluous neuroscience information makes explanations of psychological phenomena more appealing. Journal of Cognitive Neuroscience, 27(5), 926-944. doi:http://dx.doi.org.proxy.library.carleton.ca/10.1162/jocn_a_00750

Fischer-Baum, S., Dickson, D. S., \& Federmeier, K. D. (2014). Frequency and regularity effects in reading are task dependent: Evidence from ERPs. Language, Cognition and Neuroscience, 29(10), 1342-1355. http://doi.org/10.1080/23273798.2014.927067

Fischler, I. (1977). Semantic facilitation without association in a lexical decision task. Memory \& Cognition, 5(3), 335-339. doi:http://dx.doi.org.proxy.library.carleton.ca/10.3758/BF03197580

Forstmann, B. U., Ratcliff, R., \& Wagenmakers, E. -. (2016). Sequential sampling models in cognitive neuroscience: Advantages, applications, and extensions.Annual Review of Psychology, 67, 641-666. doi:http://dx.doi.org.proxy.library.carleton.ca/10.1146/annurevpsych-122414-033645

Friedrich, J. (1996) Assessing students' perceptions of psychology as a science: validation of a self-report measure. Teaching of Psychology, 23, 6-13.

Fulmer, G. W. (2014). Undergraduates' attitudes toward science and their epistemological beliefs: Positive effects of certainty and authority beliefs. Journal of Science Education and Technology, 23(1), 198-206. doi:http://dx.doi.org.proxy.library.carleton.ca/10.1007/s10956-013-9463-7

Gardner, P. L. (1975). Attitudes to science. Studies in Science Education, 2, 1-41 
Gardner, R. M., \& Brown, D. L. (2013). A test of contemporary misconceptions in psychology. Learning and Individual Differences, 24, 211-215. doi:http://dx.doi.org.proxy.library.carleton.ca/10.1016/j.lindif.2012.12.008

Gervasio, A. H., Wendorf, C. A., \& Yoder, N. F. (2010). Validating a psychology as a helping profession scale. Teaching of Psychology, 37(2), 107-113. doi:http://dx.doi.org.proxy.library.carleton.ca/10.1080/00986281003609199

Gilbert, P. N., O'Brien, L. T., Garcia, D. M., \& Marx, D. M. (2015). "Not the sum of its parts: Decomposing implicit academic stereotypes to understand sense of fit in math and english": Erratum. Sex Roles, 72(9-10), 1-484. doi:http://dx.doi.org.proxy.library.carleton.ca/10.1007/s11199-015-0481-1

Gonsalkorale, K., Allen, T. J., Sherman, J. W., \& Klauer, K. C. (2010). Mechanisms of group membership and exemplar exposure effects on implicit attitudes. Social Psychology, 41(3), 158-168. doi:http://dx.doi.org.proxy.library.carleton.ca/10.1027/18649335/a000023

Gordon, B. (1983). Lexical access and lexical decision: Mechanisms of frequency sensitivity. Journal of Verbal Learning \& Verbal Behavior, 22(1), 24-44. doi:http://dx.doi.org.proxy.library.carleton.ca/10.1016/S0022-5371(83)80004-8

Greene, E., \& Cahill, B. S. (2012). Effects of neuroimaging evidence on mock juror decision making. Behavioral Sciences \& the Law, 30(3), 280-296. doi:http://dx.doi.org.proxy.library.carleton.ca/10.1002/bsl.1993

Greenwald, A. G., \& Banaji, M. R. (1995). Implicit social cognition: Attitudes, self-esteem and stereotypes. Psychological Review, 102, 4-27. 
Greenwald, A. G., McGhee, D. E., \& Schwartz, J. K. L. (1998). Measuring individual differences in implicit cognition: The Implicit Association Test. Journal of Personality and Social Psychology, 74, 1464-1480. doi:10.1037/0022-3514.74.6.1464.

Gruber \& Dickerson 2012

Gurley, J. R., \& Marcus, D. K. (2008). The effects of neuroimaging and brain injury on insanity defenses. Behavioral Sciences \& the Law, 26(1), 85-97. doi:http://dx.doi.org.proxy.library.carleton.ca/10.1002/bsl.797

Hannover, B., \& Kessels, U. (2004). Self-to-prototype matching as a strategy for making academic choices. Why German high school students do not like math and science. Learning and Instruction, 14(1), 51-67

Hartwig, S. (2003). Surveying Psychologists' Public Image with Drawings of a "Typical” Psychologists. South Pacific Journal of Psychology, 14, 69-75. doi: $10.1017 / \mathrm{S} 0257543400000250$

Hartwig, S. G., \& Delin, C. (2003). How unpopular are we? reassessing psychologists' public image with different measures of favourability. Australian Psychologist, 38(1), 68-72

Hendley, D., Parkinson, J., Stables, A. and Tanner, H. (1995). Gender differences in pupil attitudes to the national curriculum foundation subjects of english, mathematics, science and technology in Key Stage 3 in South Wales. Educational Studies, 21, 85-97.

Hernandez, G. (2016). The conceptual representation of science and implications for psychology's status as a scientific discipline (Unpublished master's thesis). Carleton University, Ottawa, Canada.

Hino, Y., \& Lupker, S. J. (2000). Effects of word frequency and spelling-to-sound regularity in naming with and without preceding lexical decision. Journal of Experimental 
Psychology: Human Perception and Performance, 26(1), 166-183.

doi:http://dx.doi.org.proxy.library.carleton.ca/10.1037/0096-1523.26.1.166

Hofer, B. K. (2000). Dimensionality and disciplinary differences in personal epistemology. Contemporary Educational Psychology, 25(4), 378-405. doi:http://dx.doi.org.proxy.library.carleton.ca/10.1006/ceps.1999.1026

Hogan K, Maglienti M (2001) Comparing the epistemological underpinnings of students' and scientists' reasoning about conclusions. J Res Sci Teach 38(6):663-687

Holmes, J. D., \& Beins, B. C. (2009). Psychology is a science: At least some students think so. Teaching of Psychology, 36(1), 5-11. doi:http://dx.doi.org.proxy.library.carleton.ca/10.1080/00986280802529350

Hook, C. J., \& Farah, M. J. (2013). Look again: Effects of brain images and mind-brain dualism on lay evaluations of research. Journal of Cognitive Neuroscience, 25(9), 1397-1405. doi:http://dx.doi.org.proxy.library.carleton.ca/10.1162/jocn_a_00407

Hopkins, E. J., Weisberg, D. S., \& Taylor, J. C. V. (2016). The seductive allure is a reductive allure: People prefer scientific explanations that contain logically irrelevant reductive information. Cognition, 155, 67-76. doi:http://dx.doi.org.proxy.library.carleton.ca/10.1016/j.cognition.2016.06.011

Howell, J. L., Collisson, B., \& King, K. M. (2014). Physics envy: Psychologists' perceptions of psychology and agreement about core concepts. Teaching of Psychology, 41(4), 330-334. doi:http://dx.doi.org.proxy.library.carleton.ca/10.1177/0098628314549705

Ikeda, K., Kitagami, S., Takahashi, T., Hattori, Y., \& Ito, Y. (2013). Neuroscientific information bias in metacomprehension: The effect of brain images on metacomprehension judgment of neuroscience research. Psychonomic Bulletin \& Review, 20(6), 1357-1363. 
Janda, L. H., England, K., Lovejoy, D., \& Drury, K. (1998). Attitudes Toward Psychology Relative to Other Disciplines. Professional Psychology: Research and Practice, 29(2): $140-143$

Jehng, J. J., Johnson, S. D., and Anderson, R. C. (1993). Schooling and student' s

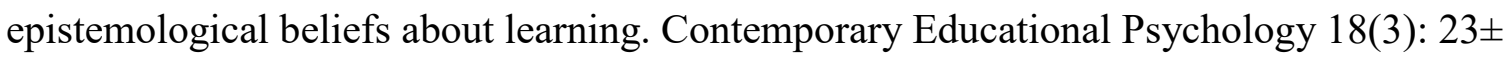
35.

Johnstone, A. H. (1991). Why is science difficult to learn? things are seldom what they seem. Journal of Computer Assisted Learning, 7(2), 75-83. doi:http://dx.doi.org.proxy.library.carleton.ca/10.1111/j.1365-2729.1991.tb00230.x

Keil, F. C., Lockhart, K. L., \& Schlegel, E. (2010). A bump on a bump? emerging intuitions concerning the relative difficulty of the sciences. Journal of Experimental Psychology: General, 139(1), 1-15. doi:http://dx.doi.org.proxy.library.carleton.ca/10.1037/a0018319

Keil, F. C. (2006). Explanation and understanding. Annual Review of Psychology, 57, 227-254. doi:http://dx.doi.org.proxy.library.carleton.ca/10.1146/annurev.psych.57.102904.1

Kessels, U., \& Hannover, B. (2004). Empfundene Selbstnaehe als Mediator zwischen Faehigkeitsselbstkonzept und Leistungskurswahlintentionen [Self-closeness: A mediator between self-concept of ability and subject major course selection intentions]. Zeitschrift fuer Entwicklungspsychologie und Paedagogische Psychologie, 36, 130-138.

Kessels, U., Rau, M., \& Hannover, B. (2006). What goes well with physics? measuring and altering the image of science. British Journal of Educational Psychology, 76(4), 761-780. doi:http://dx.doi.org.proxy.library.carleton.ca/10.1348/000709905X59961

King, M. P., \& Kitchner, K. S. (1994). Developing reflective judgment. San Francisco: JosseyBass Publishers. 
Kluger, A. N., \& Tikochinsky, J. (2001). The error of accepting the theoretical null hypothesis: The rise, fall, and resurrection of common sense hypotheses in psychology. Psychological Bulletin.

Koole, S. L., Dijksterhuis, A., \& van Knippenberg, A. (2001). What's in a name: Implicit selfesteem and the automatic self. Journal of Personality and Social Psychology, 80(4), 669685. doi:http://dx.doi.org.proxy.library.carleton.ca/10.1037/0022-3514.80.4.669

Krull, D. S., \& Silvera, D. H. (2013). The stereotyping of science: Superficial details influence perceptions of what is scientific. Journal of Applied Social Psychology, 43(8), 16601667. doi:http://dx.doi.org.proxy.library.carleton.ca/10.1111/jasp.12118

Kuhn, D., Garcia-Mila, M., Zohar, A., \& Andersen, C. (1995). Strategies of knowledge acquisition. Monographs of the Society for Research in Child Development, Serial No. $245,60(4)$.

Lane, K. A., Goh, J. X., \& Driver-Linn, E. (2012). Implicit science stereotypes mediate the relationship between gender and academic participation. Sex Roles, 66(3-4), 220-234. doi:http://dx.doi.org.proxy.library.carleton.ca/10.1007/s11199-011-0036-z

Leong, F. T. L., Conant, L., \& Zachar, P. (2004) Cognitive processing styles associated with scientist and practitioner interests in psychology. Unpublished manuscript, University of Tennessee, Knoxville.

Leong, F. T. L., \& Zachar, P. (1991). Development and validation of the scientist-practitioner inventory for psychology. Journal of Counseling Psychology, 38(3), 331-341. doi:http://dx.doi.org.proxy.library.carleton.ca/10.1037/0022-0167.38.3.331 
Leong, F. T. L., \& Zachar, P. (1993). Presenting two brief versions of the scientist practitioner inventory. Journal of Career Assessment, 1(2), 162-170. doi:http://dx.doi.org.proxy.library.carleton.ca/10.1177/106907279300100205

Lilienfeld, S. O. (2011). Public Skepticism of Psychology: Why Many People Perceive the Study of Human Behavior as Unscientific. American Psychologist, 67: 111-129.

Lilienfeld, S. O. (2012). Public skepticism of psychology: Why many people perceive the study of human behavior as unscientific. American Psychologist, 67(2), 111-129. doi:http://dx.doi.org.proxy.library.carleton.ca/10.1037/a0023963

Lilienfeld, S. O., Lynn, S. J., Ruscio, J., \& Beyerstein, B. L. (2010). 50 great myths of popular psychology: Shattering widespread misconceptions about human behavior. Chichester, England: Wiley-Blackwell.

Lund, K., \& Burgess, C. (1996) Producing high-dimensional semantic spaces from lexical cooccurrence. Behavior Research Methods, Instruments, \& Computers, 28, 203-208.

Lutus, P. (2013). The Trouble with Psychology: Serious obstacles hinder a scientific study of the mind. Retrieved February 3, 2016.

Lutus, P. (2015). The Scientific Paradigm. Retrieved February 2, 2016, from http://arachnoid.com/scientific_paradigm/

Manning, K., Zachar, P., Ray, G. E., \& LoBello, S. (2006). Research methods courses and the scientist and practitioner interests of psychology majors. Teaching of Psychology, 33(3), 194-196. Retrieved from http://proxy.library.carleton.ca/login?url=http://search.proquest.com.proxy.library.carleto $\underline{\text { n.ca/docview } / 621381228 ? \text { accountid }=9894}$ 
Markus, H., \& Zajonc, R. B. (1985). The cognitive perspective in social psychology. In G. Lindzey \& E. Aronson (Eds.), The handbook of social psychology (Vol. 1, 3rd ed., pp. 137-230). New York: Random House.

McCabe, D. P., \& Castel, A. D. (2008). Seeing is believing: The effect of brain images on judgments of scientific reasoning. Cognition, 107(1), 343-352. doi:http://dx.doi.org.proxy.library.carleton.ca/10.1016/j.cognition.2007.07.017

Meyer, D. E., \& Schvaneveldt, R. W. (1971). Facilitation in recognizing pairs of words: Evidence of a dependence between retrieval operations. Journal of Experimental Psychology, 90(2), 227-234. doi:http://dx.doi.org.proxy.library.carleton.ca/10.1037/h0031564

Michael, R. B., Newman, E. J., Vuorre, M., Cumming, G., \& Garry, M. (2013). On the (non)persuasive power of a brain image. Psychonomic Bulletin \& Review, 20(4), 720 725. doi:http://dx.doi.org.proxy.library.carleton.ca/10.3758/s13423-013-0391-6

Miller, G. A. (2010). Mistreating psychology in the decades of the brain. Perspectives on Psychological Science, 5, 716 -743. doi:10.1177/ 1745691610388774

Morales, B. L., Abramson, C. I., Nain, S., Junior, N. A., \& Bartoszeck, A. B. (2005) Status of psychology as a science in northeast Brazil: undergraduate students' perceptions. Psychological Reports, 96, 109-114.

Morgan, L., (2015). The Mental Representation of Psychology as Non-Scientific: A cognitive approach to understanding the perception of psychology.

Morgan, L., (2017). The Perception of Psychology as Unscientific: The cognitive mechanisms underlying the perceptions that psychology is not a science 
Moss, H. E., Ostrin, R. K., Tyler, L. K., \& Marslen-Wilson, W. (1995). Accessing different types of lexical semantic information: Evidence from priming. Journal of Experimental Psychology: Learning, Memory, and Cognition, 21(4), 863-883. doi:http://dx.doi.org.proxy.library.carleton.ca/10.1037/0278-7393.21.4.86

Murstein, B. I., \& Fontaine, P. A. (1993). The public's knowledge about psychologists and other mental health professionals. American Psychologist, 48(7), 839-845. doi:http://dx.doi.org.proxy.library.carleton.ca/10.1037/0003-066X.48.7.839

Mutch, H. E. (2010). A phenomenographical study of student learning in general college chemistry (Order No. AAI3360444). Available from PsycINFO. (622190013; 2010 99020-427). Retrieved from http://search.proquest.com.proxy.library.carleton.ca/docview/622190013?accountid=984

Nosek, B. A., \& Banaji, M. R. (2001). The Go/No-go association task. Social Cognition, 19(6), 625-666. doi:http://dx.doi.org.proxy.library.carleton.ca/10.1521/soco.19.6.625.20886

Nosek, B. A., \& Smyth, F. L. (2011). Implicit social cognitions predict sex differences in math engagement and achievement. American Educational Research Journal. doi:10.3102/0002831211410683. Advance online publication.

Nosek, B. A., Banaji, M. R., \& Greenwald, A. G. (2002). Math= Male, Me=Female, therefore Math $\neq$ Me. Journal of Personality and Social Psychology, 83, 44-59. doi:10.1037/00223514.83.1.44

Nosek, B. A., Smyth, F. L., Sriram, N., Lindner, N. M., Devos, T., Ayala, A., et al. (2009). National differences in gender-science stereotypes predict national sex differences in science and math achievement. Proceedings of the National Academy of Sciences, USA, 106, 10593-10597. doi:10.1073/pnas.0809921106 
Osborne, J. F. and Collins, S. (2000). Pupils' and parents' views of the school science curriculum (London: King's College London).

Osborne, J. F., Simon, S. \& Collins, S. (2003). Attitudes towards Science: A review of the literature and its implications. International Journal of Science Education, 25, 10491079.

Paulsen, M. B., \& Wells, C. T. (1998). Domain differences in the epistemological beliefs of college students. Research in higher education, 39(4), 365-384.

Penn, Schoen and Berland Associates. (2008). American Psychological Association benchmark study. New York, NY: Author.

Perea, M., Rosa, E., \& Gómez, C. (2002). Is the go/no-go lexical decision task an alternative to the yes/no lexical decision task? Memory \& Cognition, 30(1), 34-45. doi:http://dx.doi.org.proxy.library.carleton.ca/10.3758/BF03195263

Perry, W. G., Jr. (1970). Forms of intellectual and ethical development in the college years Holt, Rinehart \& Winston, Oxford. Retrieved from http://proxy.library.carleton.ca/login?url=https://search-proquestcom.proxy.library.carleton.ca/docview/615687650?accountid=9894

Pettijohn, Terry F.,II, Pettijohn, T. F., Brenneman, M. M., Glass, J. N., Brito, G. R., Terranova, A. M., Piroch, J. (2015). College student perceptions of psychology as a science as a function of psychology course enrollment. College Student Journal, 49(3), 461-465. Retrieved from http://proxy.library.carleton.ca/login?url=http://search.proquest.com.proxy.library.carleto $\underline{\text { n.ca/docview } / 1721926635 \text { ?accountid }=9894}$ 
Petty RE, Tormala ZL, Brinol P, Jarvis WBG. 2006. Implicit ambivalence from attitude change: an exploration of the PAST model. J. Personal. Soc. Psychol. 90:21-41

Plagianakos, D. (2016). Psychology and Science: Same Difference? Understanding Psychology's Relationship to the Hard Sciences using Multidimensional Scaling (Unpublished thesis). Carleton University, Ottawa, Canada.

Provost, S. C., Martin, F. H., Peacock, A., Lipp, O. V., Bath, D., \& Hannan, G. (2011). University students' views on the nature of science and psychology. Psychology Learning \& Teaching, $10(2), 128-145$.

doi:http://dx.doi.org.proxy.library.carleton.ca/10.2304/plat.2011.10.2.128

Psychology Software Tools, Inc. [E-Prime 2.0]. (2012). Retrieved from http://www.pstnet.com.

Redding, R. E. (1998). How common-sense psychology can inform law and psycholegal research. The University of Chicago Law School Roundtable, 5, 107-142.

Rhodes, R. E., Rodriguez, F., \& Shah, P. (2014). Explaining the alluring influence of neuroscience information on scientific reasoning. Journal of Experimental Psychology: Learning, Memory, and Cognition, 40(5), 1432-1440.

doi:http://dx.doi.org.proxy.library.carleton.ca/10.1037/a0036844

Roberts, G. (2002). SET for success. The supply of people with science, technology, engineering and mathematics skills (The Report of Sir Gareth Roberts's Review). London: HM Treasury

Roeckelein, J. E. (1997). Hierarchy of the sciences and terminological sharing of laws among the sciences. Psychological Reports, 81(3), 739-746. Retrieved from http://proxy.library.carleton.ca/login?url=http://search.proquest.com.proxy.library.carleto n.ca/docview/619200161?accountid $=9894$ 
Rosenthal, G. T., McKnight, R. R., \& Price, A. W. (2001). Who, what, how, and where the typical psychologist is...the profession of psychology scale. Journal of Instructional Psychology, 28(4), 220-224. Retrieved from

http://proxy.library.carleton.ca/login?url=http://search.proquest.com.proxy.library.carleto $\underline{\text { n.ca/docview } / 619648277 \text { ?accountid }=9894}$

Rozenblit, L., \& Keil, F. (2002). The misunderstood limits of folk science: An illusion of explanatory depth. Cognitive Science, 26(5), 521-562.

doi:http://dx.doi.org.proxy.library.carleton.ca/10.1016/S0364-0213(02)00078-2

Ryan, M. (2015). Who is like a scientist? a self-prototype matching approach to women's underrepresentation in stem fields (Order No. AAI3641625). Available from PsycINFO. (1709218763; 2015-99161-097). Retrieved from http://proxy.library.carleton.ca/login?url=http://search.proquest.com.proxy.library.carleto $\underline{\text { n.ca/docview } / 1709218763 ? \text { accountid }=9894}$

Schaeffer, B., \& Wallace, R. (1969). Semantic similarity and the comparison of word meanings. Journal of Experimental Psychology, 82(2), 343-346. doi:http://dx.doi.org.proxy.library.carleton.ca/10.1037/h0028287

Scherer, L. D., \& Lambert, A. J. (2009). Contrast effects in priming paradigms: Implications for theory and research on implicit attitudes. Journal of Personality and Social Psychology, 97(3), 383-403. doi:http://dx.doi.org.proxy.library.carleton.ca/10.1037/a0015844

Schommer, M. (1994). Synthesizing epistemological belief research: Tentative understandings and provocative confusions. Educational Psychology Review, 6(4), 293-319. doi:http://dx.doi.org.proxy.library.carleton.ca/10.1007/BF02213418 
Schommer, M., \& Walker, K. (1995). Are epistemological beliefs similar across domains? Journal of Educational Psychology, 87(3), 424-432. doi:http://dx.doi.org.proxy.library.carleton.ca/10.1037/0022-0663.87.3.424

Schvaneveldt, R.W.; Meyer, D.E. (1973), "Retrieval and comparison processes in semantic memory", in Kornblum, S., Attention and performance IV, New York: Academic Press, pp. 395-409

Schweitzer, N. J., \& Saks, M. J. (2011). Neuroimage evidence and the insanity defense. Behavioral Sciences \& the Law, 29(4), 592-607. doi:http://dx.doi.org.proxy.library.carleton.ca/10.1002/bsl.995

Schweitzer, N. J., Saks, M. J., Murphy, E. R., Roskies, A. L., Sinnott-Armstrong, W., \& Gaudet, L. M. (2011). Neuroimages as evidence in a mens rea defense: No impact. Psychology, Public Policy, and Law, 17(3), 357-393. doi:http://dx.doi.org.proxy.library.carleton.ca/10.1037/a0023581

Segui, J., Mehler, J., Frauenfelder, U., \& Morton, J. (1982). The word frequency effect and lexical access. Neuropsychologia, 20(6), 615-627.

Simonton, D. K. (2004). Psychology's status as a scientific discipline: Its empirical placement within an implicit hierarchy of the sciences. Review of General Psychology, 8, 59-67.

Sizemore, O.J. \& Gary W. Lewandowski Jr. (2009) Learning Might Not Equal Liking: Research Methods Course Changes Knowledge but Not Attitudes, Teaching of Psychology, 36:2, 90-95, DOI: $10.1080 / 00986280902739727$

Smyth, M. M. (2001). Fact making in psychology: The voice of the introductory textbook. Theory \& Psychology, 11(5), 609-636. doi:http://dx.doi.org.proxy.library.carleton.ca/10.1177/0959354301115002 
Stanovich, K. E. (2013). How to Think Straight About Psychology. New Jersey: Pearson Education, Inc.

Stanovich, K. E. (2009). What intelligence tests miss: The psychology of rational thought. New Haven, CT: Yale University Press.

Storer, Norman. 1967. "The Hard Sciences and the Soft: Some Sociological Observations." Bulletin of the Medical Library Association 55:75-84.

The Research Business (1994). Views of science among students, teachers and parents (London: Institution of Electrical Engineers).

Thomas MA, Neely JH, O’Connor P. (2012). When word identification gets tough, retrospective semantic processing comes to the rescue. Journal of Memory and Language. 2012;66(4):623-643.

Thomas, M. D., Henley, T. B., \& Snell, C. M. (2006). The draw a scientist test: A different population and a somewhat different story. College Student Journal, 40(1), 140-148. Retrieved from http://proxy.library.carleton.ca/login?url=http://search.proquest.com.proxy.library.carleto $\underline{\text { n.ca/docview/621161996? accountid }=9894}$

Van Selst, M., \& Jolicoeur, P. (1994). A solution to the effect of sample size on outlier elimination. The Quarterly Journal of Experimental Psychology A: Human Experimental Psychology, 47a(3), 631-650.

doi:http://dx.doi.org.proxy.library.carleton.ca/10.1080/14640749408401131

Vitevitch, M. S., Stamer, M. K., \& Sereno, J. A. (2008). Word length and lexical competition: Longer is the same as shorter. Language and Speech, 51(4), 361-383. doi:http://dx.doi.org.proxy.library.carleton.ca/10.1177/0023830908099070 
Von Sydow, K., \& Reimer, C. (1997). Attitudes toward psychotherapists, psychologists, psychiatrists, and psychoanalysts. A meta-content analysis of 60 studies published between 1948 and 1995. American journal of psychotherapy, 52(4), 463-488.

Wade, N. (1982, April 30). Smart apes or dumb? The New York Times, A28.

Watson, J., Dawson, A., \& McEwen, S. (1994). Sixth form A level students' perceptions of the difficulty, intellectual freedom, social benefit and interest of science and arts subjects. Research in Science and Technological Education, 12(1), 43-52.

Webb, A. R. (1988). Psychology as an ambiguous attitude stimulus. American Psychologist, 43(6), 487-488. doi:http://dx.doi.org.proxy.library.carleton.ca/10.1037/0003-066X.43.6.487

Webb, A. R., \& Speer, J. R. (1985). The public image of psychologists. American Psychologist, 40(9), 1063-1064. doi:http://dx.doi.org.proxy.library.carleton.ca/10.1037/0003-066X.40.9.1063.b

Webb, A. R., \& Speer, J. R. (1986). Prototype of a profession: Psychology's public image. Professional Psychology: Research and Practice, 17(1), 5-9. doi:http://dx.doi.org.proxy.library.carleton.ca/10.1037/0735-7028.17.1.5

Weisberg, D. S., Keil, F. C., Goodstein, J., Rawson, E., \& Gray, J. R. (2008). The seductive allure of neuroscience explanations. Journal of Cognitive Neuroscience, 20(3), 470-477. doi:http://dx.doi.org.proxy.library.carleton.ca/10.1162/jocn.2008.20040

Weisberg, D. S., Taylor, J. C. V., \& Hopkins, E. J. (2015). Deconstructing the seductive allure of neuroscience explanations. Judgment and Decision Making, 10(5), 429-441. Retrieved from 
http://proxy.library.carleton.ca/login?url=http://search.proquest.com.proxy.library.carleto n.ca/docview/1727668644? accountid $=9894$

Whitehead, J. M. (1996). Sex stereotypes, gender identity and subject choice at A level. Educational Research, 38, 147-160.

Wilson, T. D., Lindsey, S., \& Schooler, T. (2000). A model of dual attitudes. Psychological Review, 107, 101-126. doi:10.1037/ 0033-295X.107.1.101.

Wittenbrink, B., Judd, C. M., \& Park, B. (2001). Spontaneous prejudice in context: Variability in automatically activated attitudes. Journal of Personality and Social Psychology, 81(5), 815-827. doi:http://dx.doi.org.proxy.library.carleton.ca/10.1037/0022-3514.81.5.815

Wood, W., Jones, M., \& Benjamin, L. T., Jr. (1986). Surveying psychology’s public image. American Psychologist, 41, 947-953. oi:10.1037/ 0003-066X.41.9.947

Zachar, P., \& Leong, F. T. (1992). A problem of personality: Scientist and practitioner differences in psychology. Journal of Personality, 60(3), 665-677. doi:http://dx.doi.org.proxy.library.carleton.ca/10.1111/j.1467-6494.1992.tb00925.x Zimmerman, C., Gerson, S., Monroe, A., \& Kearney, A. M. (2007). Physics is harder than psychology (or is it?): Developmental differences in calibration of domain-specific texts. In D. S. McNamara \& J. G. Trafton (Eds.), Proceedings of the Twenty-Ninth Annual Cognitive Sci- ence Society (pp. 1683-1688). Austin, TX: Cognitive Science Society. 
Appendix A: FSG between Scientific Disciplines and Subject Matter

\begin{tabular}{lll}
\hline Scientific Discipline & Subject Matter & FSG \\
\hline Biology & Animal & 0.1329 \\
Chemistry & Chemical & 0.1984 \\
Physics & Gravity & 0.0568 \\
Psychology & Mind & 0.2784 \\
Psychology & Brain & 0.1649 \\
Psychology & Behaviour & 0.0515 \\
Neuroscience & Brain & 0.6561 \\
Neuroscience & Mind & 0.0295 \\
\hline
\end{tabular}


Appendix B: List of Non-Words

\begin{tabular}{lrlll}
\hline Word & HAL Frequency & Matched Word & HAL Frequency & Non-Word \\
\hline analysis & 10.77 & multiple & 10.71 & miltuple \\
animal & 10.12 & guitar & 10.12 & guatir \\
behavior & 10.31 & distance & 10.3 & dastince \\
biology & 9.28 & signals & 9.3 & sagnils \\
brain & 10.9 & gives & 10.91 & gevis \\
chemical & 9.64 & digested & 9.61 & degisted \\
chemistry & 9.45 & indicates & 9.48 & indacites \\
difficult & 10.87 & generally & 10.82 & ganerelly \\
easy & 11.45 & stop & 11.48 & sopt \\
experiment & 9.49 & contribute & 9.48 & contrubite \\
fact & 12.13 & sold & 12.15 & slod \\
gravity & 9.24 & senator & 9.24 & sanetor \\
hypothesis & 8.64 & widespread & 8.63 & weadsprid \\
important & 11.57 & technical & 11.49 & tachnicel \\
mind & 11.78 & kind & 11.79 & knid \\
neurology & 5.94 & misinterpret & 5.99 & mesinterprit \\
observation & 9.12 & communities & 9.17 & cummonities \\
physics & 10.28 & regards & 10.28 & ragerds \\
psychology & 9.22 & purchasing & 9.2 & parchusing \\
science & 11.51 & started & 11.5 & stertad \\
subjective & 8.62 & obligation & 8.63 & oblagition \\
useless & 9.51 & charged & 9.46 & chergad \\
\hline
\end{tabular}

Note. HAL Frequency refers to the Hyperspace Analogue to Language (Lund \& Burgess, 1996) frequency norms, which have been log transformed. 
Appendix C: Practice Trial Words and Non-Words

\begin{tabular}{lllll}
\hline Word & HAL Frequency & Matched Word & HAL Frequency & Non-Word \\
\hline apple & 11.1 & cover & 11.07 & cevor \\
avocado & 5.7 & spirals & 5.57 & sparils \\
fruit & 9.28 & loves & 2.29 & levos \\
tangerine & 6.05 & adoration & 6.07 & adarotion \\
\hline \multicolumn{2}{l}{ Note. HAL Frequency refers to the Hyperspace Analogue to Language (Lund \& Burgess, 1996) } \\
frequency norms, which have been log transformed.
\end{tabular}


Appendix D: Psychology as a Science Scale

\section{Factor One}

1. An undergraduate degree in psychology should be a Bachelor of Science rather than a Bachelor of Arts degree.

2. It's just as important for psychology Students to do experiments as it is for students in chemistry and biology.

3. Government funding of experimentation is as necessary for expanding what we know about psychology as it is for gaining knowledge in-areas like chemistry and physics.

4. The study of psychology should be seen primarily as a science.

5. Psychological advice given in popular books and magazines is often as useful as more research-based claims.

\section{Factor Two}

6. Courses in psychology place too much emphasis on research and experimentation.

7. Psychologists working as counseling professionals don't need to be so concerned with research findings

8. Psychological theories presented in the media should not be trusted unless they are supported by experiments.

9. Students get little benefit from learning about procedures for conducting psychology experiments

Factor Three

10. Research conducted in controlled laboratory settings is essential for understanding everyday behaviour.

11. Even though each person is unique, it is possible for science to find general laws explaining human behaviour.

12. Carefully controlled research is not likely to be useful in solving psychological problems.

13. Our ability as humans to behave in any way we choose makes our attempts to predict behaviour ineffective.

14. Psychological research can enable us to anticipate people's behaviour with a high degree of accuracy.

15. Psychology will never be a true science because its predictions about individual behaviour are seldom exact or certain.

Filler questions

A psychology course is an important part of any person's college education. The different areas within psychology seem very unrelated to each other.

An introductory psychology course should cover as broad a range of topics as possible. Studying specific examples of how psychology is used is the most interesting part of a psychology course.

Psychology courses should spend time covering various job possibilities for people with psychology degrees. 
Appendix E: Scientist-Practitioner Inventory

Interest in Practitioner Activities

1. Learning new strategies for dealing with psychological problems

2. Planning a behaviour modification program for a client

3. Designing a new treatment method for a mental health agency

4. Reading a book written by a famous psychotherapist

5. Interpreting a test battery for a client

6. Presenting a report during a clinical case conference

7. Reviewing an agency's intake form for a new client

8. Conducting couples and family therapy

9. Reviewing journal articles

Interest in Scientific Activities

10. Serving as an editor for a scientific journal

11. Writing a scientific book for psychologists

12. Developing new explanations of well accepted empirical studies

13. Serving on a thesis or dissertation committee

14. Reading a book on innovative research designs

15. Collecting data on a research project you designed

16. Learning about a new statistical procedures

17. Receiving therapy to make yourself a better person

18. Applying for research grants. 
Appendix F: Lexical Characteristics for Word Stimuli

\begin{tabular}{|c|c|c|c|}
\hline Stimuli & Frequency Count & Number of Letters & Number of Syllables \\
\hline analysis & 563 & 8 & 4 \\
\hline animal & 2320 & 6 & 3 \\
\hline behavior & 1142 & 8 & 3 \\
\hline biology & 250 & 7 & 4 \\
\hline brain & 3928 & 5 & 1 \\
\hline chemical & 579 & 8 & 3 \\
\hline chemistry & 442 & 9 & 3 \\
\hline difficult & 3068 & 9 & 3 \\
\hline easy & 13551 & 4 & 2 \\
\hline experiment & 826 & 10 & 4 \\
\hline fact & 8801 & 4 & 1 \\
\hline gravity & 351 & 7 & 3 \\
\hline hypothesis & 44 & 10 & 4 \\
\hline important & 10587 & 9 & 3 \\
\hline mind & 24715 & 4 & 1 \\
\hline neuroscience & 2 & 12 & 4 \\
\hline observation & 380 & 11 & 4 \\
\hline physics & 482 & 7 & 2 \\
\hline psychology & 279 & 10 & 4 \\
\hline science & 1900 & 7 & 2 \\
\hline subjective & 57 & 10 & 3 \\
\hline useless & 1017 & 7 & 2 \\
\hline
\end{tabular}

Note. Frequency Counts were obtained using the Subtlexus' word frequency database (Brysbaert \& New, 2009). 